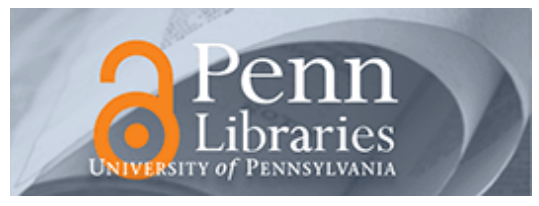

University of Pennsylvania

ScholarlyCommons

Finance Papers

Wharton Faculty Research

$9-2015$

\title{
A Positive Theory of Economic Growth and the Distribution of Income
}

Allan H. Meltzer

Scott F. Richard

University of Pennsylvania

Follow this and additional works at: https://repository.upenn.edu/fnce_papers

Part of the Finance and Financial Management Commons, and the Income Distribution Commons

\section{Recommended Citation}

Meltzer, A. H., \& Richard, S. F. (2015). A Positive Theory of Economic Growth and the Distribution of Income. Research in Economics, 69 (3), 265-290. http://dx.doi.org/10.1016/j.rie.2015.04.001

This paper is posted at ScholarlyCommons. https://repository.upenn.edu/fnce_papers/204

For more information, please contact repository@pobox.upenn.edu. 


\title{
A Positive Theory of Economic Growth and the Distribution of Income
}

\begin{abstract}
This paper is a positive theory of the distribution of income and the growth rate of the economy. It builds on our earlier work (Meltzer and Richard, 1981) on the size of government. How does the distribution of income change as an economy grows? To answer this question we build a model of a labor economy in which consumers have diverse productivity. The government imposes a linear income tax which funds equal per capita redistribution. The tax rate is set in a sequence of single issue election in which the median productivity individual is decisive. Economic growth is the result of using a learning by doing technology, so higher taxes discourage labor causing the growth rate of the economy to fall. The distribution of productivity can widen due to an exogenous increase in technological specialization. This causes voters to raise the equilibrium tax rate and reduce growth. The distribution of pre-tax income widens. We calibrate the model using data from the U.S., U.K. and France. The results of the calibration show that the model is consistent with the facts about changes in income distribution over time in developed countries.
\end{abstract}

Keywords

income distribution, size of government, median voter theorem

Disciplines

Economics | Finance and Financial Management | Income Distribution 


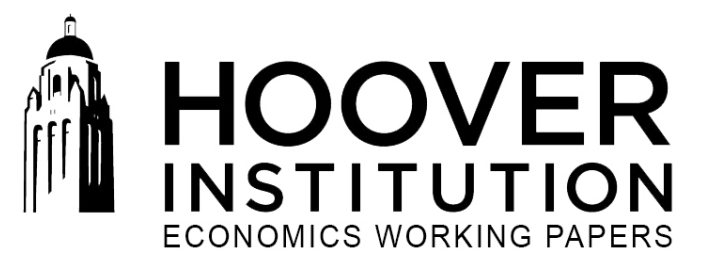

\title{
A Positive Theory of Economic Growth and the Distribution of Income
}

\author{
Allan H. Meltzer and Scott F. Richard* \\ Economics Working Paper 15110 \\ HOOVER INSTITUTION \\ 434 GALVEZ MALL \\ STANFORD UNIVERSITY \\ STANFORD, CA 94305-6010
}

April 4, 2015

This paper is a positive theory of the distribution of income and the growth rate of the economy. It builds on our earlier work, Meltzer and Richard (1981), on the size of government. How does the distribution of income change as an economy grows? To answer this question we build a model of a labor economy in which consumers have diverse productivity. The government imposes a linear income tax which funds equal per capita redistribution. The tax rate is set in a sequence of single issue election in which the median productivity individual is decisive. Economic growth is the result of using a learning by doing technology, so higher taxes discourage labor causing the growth rate of the economy to fall. The distribution of productivity can widen due to an exogenous increase in technological specialization. This causes voters to raise the equilibrium tax rate and reduce growth. The distribution of pre-tax income widens. We calibrate the model using data from the U.S., U.K. and France. The results of the calibration show that the model is consistent with the facts about changes in income distribution over time in developed countries.

* We wish to thank V.V. Chari, Marvin Goodfriend, the seminar particpants at the Wharton School, and the Editor for useful comments.

The Hoover Institution Economics Working Paper Series allows authors to distribute research for discussion and comment among other researchers. Working papers reflect the views of the authors and not the views of the Hoover Institution. 


\title{
A Positive Theory of Economic Growth and the Distribution of Income*
}

\author{
Allan H. Meltzer \\ The Tepper School \\ Carnegie-Mellon University \\ Pittsburgh, PA \\ am05@andrew.cmu.edu
}

\author{
Scott F. Richard \\ The Wharton School \\ University of Pennsylvania \\ Philadelphia, PA \\ scottri@wharton.upenn.edu
}

First Draft: July 4, 2014

Current Draft: April 4, 2015

(C)Allan H. Meltzer and Scott F. Richard

All Rights Reserved

\begin{abstract}
This paper is a positive theory of the distribution of income and the growth rate of the economy. It builds on our earlier work, Meltzer and Richard (1981), on the size of government. How does the distribution of income change as an economy grows? To answer this question we build a model of a labor economy in which consumers have diverse productivity. The government imposes a linear income tax which funds equal per capita redistribution. The tax rate is set in a sequence of single issue election in which the median productivity individual is decisive. Economic growth is the result of using a learning by doing technology, so higher taxes discourage labor causing the growth rate of the economy to fall. The distribution of productivity can widen due to an exogenous increase in technological specialization. This causes voters to raise the equilibrium tax rate and reduce growth. The distribution of pre-tax income widens. We calibrate the model using data from the U.S., U.K. and France. The results of the calibration show that the model is consistent with the facts about changes in income distribution over time in developed countries.
\end{abstract}

\section{Introduction}

How does the distribution of income change as economic growth changes? How does growth change when governments raise tax rates to finance increased re-

*We wish to thank V. V. Chari, Marvin Goodfriend, the seminar participants at the Wharton School, and the Editor for useful comments. 
distribution? Economists have discussed these issues for decades, and they have recently become major political issues in developed economies.

To answer these questions, we analyze a general equilibrium model under certainty of a labor economy in which there is no capital or other means of saving. Why a labor economy? Over the past two hundred years real wages in industrialized countries have increased twenty-fold while the real return to capital has remained about the same. The increase in real wages reflects the enormous increase in labor productivity based on the growth of "know-how". Capital flows to the places where labor productivity is growing. Hence in our view, capital accumulation is primarily the result, not the principal cause, of the growth in output.

To analyze our hypothesis we construct a model where consumers differ in their relative productivity. There is no labor mobility, i.e., if a consumer is originally in the 10th percentile of productivity he will be there forever. What changes is how much he produces per hour of labor. His output per hour can change because exogenous technological change can spread or shrink the entire distribution of relative productivity or because endogenous learning-by-doing causes the absolute productivity of all workers to grow. The wage rate is equal to absolute productivity so a consumer's labor income is the wage rate multiplied by his relative productivity adjusted labor.

There is a government in our model which levies a linear tax on labor income. Tax revenues finance government spending for redistribution; the real government budget is balanced. No matter how the government sets the linear tax rate, a tax increase lowers aggregate hours worked, hence lowering current aggregate income and consumption. Reducing aggregate hours worked reduces the growth of wages because there is less learning-by-doing. Hence increased taxes reduces the growth rate and widens the spread in the income distribution. Reducing tax rates and redistribution brings the opposite response.

What is the political process by which the government sets the tax rate? In our earlier work, Meltzer and Richard (1981), we rejected the idea of a benevolent government choosing the tax rate to maximize some notion of social welfare in favor of a majority rule election in which the median income voter is decisive in a single issue election to choose the tax rate. We extend our work by showing that the median voter is decisive in a series of majority rules elections for the tax rate. At all times, all consumers are fully aware of the trade-off of tax changes on redistribution and growth. At all times, the median voter chooses the trade-off he likes best.

We calibrate the model using data for the U.S., the U.K., and France. The data support the model in all three countries.

\section{A Selective Literature Survey}

The literature on economic growth and redistribution is large and varied. We report on a sample that covers different approaches and reaches very different conclusions. 
In a 1955 paper, Simon Kuznets used his extensive knowledge of income data to conclude that economic growth first increases the spread in the income distribution. The reason is that when many unskilled workers enter the labor force, the economy grows, profits rise, and higher incomes increase relatively and absolutely. As workers acquire skills, their productivity and real wages increase relative to profits, so the spread of the income distribution declines. Kuznets' conclusion has remained contentious in part because he did not produce a model showing that his result held in general equilibrium and in part because of the paucity of data he had available.

Many years later, Arthur Okun (1975) discussed the social decision of trading some efficiency or growth for more redistribution achieved by taxing higher incomes. His discussion makes the cost, called the leaky bucket, exceed the amount redistributed. His analysis, like Kuznets, concerns a one-time choice.

Our earlier work Meltzer and Richard (1981) departs from these ideas. In a functioning democratic system, voters make the choice repeatedly not once and for all times. The political choice of redistribution is like economic decisions that optimizing consumers make repeatedly. They vote either to increase current consumption by voting for a higher tax rate or they vote for growth and increased future consumption by lowering tax rates and spending. Although our earlier model is static, it is consistent with voter's decisions. Sometimes they vote for higher tax rates and spending and sometimes they do the opposite. No society chooses once for all future time.

Much of the recent literature on endogenous economic growth in general equilibrium focusses on the role of capital instead of labor. For example, Alesina and Rodrick (1994), Bertola (1993), and Persson and Tabellini (1994) all develop models of endogenous growth where consumers are endowed with diverse amounts of capital. Labor is supplied inelastically. ${ }^{1}$ Capital is taxed to fund redistribution. Higher taxes cause less growth by reducing the return to capital. The greater the heterogeneity of the distribution of capital, the higher is the preferred tax rate for the median voter. So, in general, voters will not maximize economic growth. Instead, they vote to tax capital to finance redistribution, which slows growth. Both Alesina and Rodrick (1994) and Persson and Tabellini (1994) examine the empirical implication of their models. They both conclude that income inequality is empirically negatively related to future economic growth. The reason is that as income inequality rises, voters choose more redistribution, reducing the growth rate. Much of this literature is summarized in the influential book by Acemoglu (2009).

We think that the emphasis in explaining growth should be on labor productivity not capital. Over the past 200 years real wages have increased 20 fold while the return to capital has remained basically unchanged. Politically, if capital determines growth it is difficult to understand why the taxes on capital income have risen, especially since capital is owned almost exclusively by the upper half of the income distribution. So we choose to ignore capital and focus

\footnotetext{
${ }^{1}$ In Persson and Tabellini (1994) there is no explicit labor.
} 
on labor productivity as the exclusive engine of growth. ${ }^{2}$

Another strand of the literature examines the implications of assuming high incomes are rents. Treatment of high incomes as rent permits increased taxation to finance redistribution without reducing productive activity. A special use of rents is the claim that most high incomes result from inheritance of wealth produced by an earlier generation and passed on. Evidence does not support this claim both in the U.S. and other developed countries. Kaplan and Rauh, (2013, 46, 48); Becker and Tomes $(1979,1158)$. Some work suggests that culture and educational attainment of parents has more important influence on later generations than financial inheritance. Becker and Tomes (1979, 1191), Corak $(2013,80)$

Another problem with treating high incomes, for example those of the top one percent, as rent is that the population is not fixed but changes. Piketty (2014, 115-16) writes that capital transforms "itself into rents as it accumulates in large enough amounts." Saez $(2013,24)$ concludes that "high top tax rates reduce the pre-tax income gap without visible effect on economic growth." Corak (2013) shows that intergenerational mobility remains large in developed countries like the U.S. and Canada. The main exception in the U.S. is the "least advantaged." In this paper we address the issue of why some of the least advantaged have stagnant incomes. The least productive choose not to work, so their incomes are all redistribution. Hence they do not acquire productive skills.

Much of the discussion of the top one percent makes no mention of the other 99 percent. Often, the focus is on income from capital, which neglects labor income, about $70 \%$ of total income. A very different explanation of the rising share of income earned by the top one percent builds on work on superstars by Rosen (1981). Rosen argued that technological change increases the relative productivity of individuals with exceptional talent in using and developing the new technology. Rosen's work brings in relative productivity as an explanation of the rising share of the top one percent. Developing new software, like Steve Jobs and others, that create entire markets brings high rewards. Successfully managing a bank or corporation with branches in 50 or 100 countries is an order of magnitude more difficult than managing in a single country or state. Ten years is a long tenure in such jobs, so there is turnover not inheritance of high income positions. Highly skilled surgeons adept at operating new technologies should be included.

Major league sport stars in football, baseball, soccer, basketball and hockey no longer perform before audiences restricted to a stadium. Television increased their productivity. Kaplan and Rauh (2013, 42, Figure 3) show the substantial increase in their incomes. Turnover is high; careers at the top are brief. And there is little evidence that the super stars cede their places to their offspring. Rock musicians and entertainment stars often have similar careers with high incomes for short duration. Income of super stars may explain some of

\footnotetext{
${ }^{2}$ Piguillem and Schneider (2013) add majority rule voting to the neoclassical growth model. They show that the median voter is decisive assuming that the distribution of capital is strictly proportional to the distribution of relative productivity.
} 
the increase in the relative earnings of the top one percent. We doubt that it is a full explanation because the data after 1980 show that the rise in the pre-tax share of the top one percent can be seen in the United States, the United Kingdoms, Canada and Sweden but not in France and the Netherlands. Roine and Waldenstrom (2006)

The share of pre-tax incomes received by the top one percent includes income from reported capital gains. That makes it more volatile, rising in periods when owners of shares choose to report gains in excess of losses.

There are substantial differences in the relative shares of different income quintiles when before and after tax and transfers are included. Most economic theory considers consumption, based on permanent not current income, to be a better measure of the economic component of well-being. Table 1 shows data on pre- and post-tax incomes for the United States. The data for 1979 to 2010 are available on the Congressional Budget Office website. ${ }^{3}$

\begin{tabular}{rrrrr} 
Before Tax (\%) & & & & \\
\hline Year & $\mathbf{1 9 7 9}$ & $\mathbf{1 9 8 9}$ & $\mathbf{2 0 0 7}$ & $\mathbf{2 0 1 0}$ \\
\hline & & & & \\
\hline Lowest 20\% & 6.2 & 4.9 & 4.8 & 5.1 \\
\hline Middle 20\% & 15.8 & 15 & 13.4 & 14.2 \\
\hline & & & & \\
\hline Highest 20\% & 44.9 & 49.3 & 54.6 & 51.9 \\
\hline & & & & \\
\hline Highest 1\% & 8.9 & 12.2 & 18.7 & 14.9 \\
\hline After Tax (\%) & & & & \\
\hline Lowest 20\% & 7.4 & 5.7 & 5.6 & 6.2 \\
\hline & & & & \\
\hline Middle 20\% & 16.5 & 15.7 & 14.3 & 15.4 \\
\hline & & & & \\
\hline Highest 20\% & 42 & 47.3 & 51.4 & 48.1 \\
\hline Highest 1\% & 7.4 & 11.8 & 16.7 & 12.8 \\
\hline Source: CBO (2014) & & & &
\end{tabular}

Table 1: Selected Income Shares 1979-2010 (2010 Dollars)

The range of data in Table 1 is the range given by the CBO. We chose 1989 because it was the end of the Reagan growth years. We chose 2007 because it is the peak year for the income share going to the top one percent. That year is also the peak year for the after tax share of the top one percent.

The table makes clear that it matters considerably whether analysis uses before or after tax income shares. Conceptually, income after tax and transfer is closer to consumption. By 2010 the share of after tax income received by the

\footnotetext{
${ }^{3}$ http://www.cbo.gov/publication/44604
} 
lowest 20 percent ( 6.2 percent) is the same as the before tax share received in 1979. Income shares for the lowest and middle $20 \%$ fall until 2007, then rise; the share of top one percent and 20 percent rise to 2007, then fall. Most of the rise occurs during the period of relatively high growth in the 1990s. The change is not likely to reflect changes in the return to capital. The data seems more consistent with productivity growth during the boom years.

Of interest in relation to recent discussion, the share of the upper income groups declined from 2007 to 2010. These are years of relatively slow growth combined with increased returns to equity capital and a recovery in many house prices. Again, this suggests that productivity growth is more important than return to capital in explaining income shares.

A main theme of Piketty's (2014 and elsewhere) work is that the tax rates on income and wealth should be raised even though, at some points, he recognizes that the higher rates would lower top incomes but not provide much revenue. Few of the many discussions of his work point out that the choice of tax rate should be an implication of a utility maximizing model, preferably a general equilibrium model, such as in this paper.

Long before the Piketty book stimulated renewed interest in income distribution and the choice of tax rate, Becker and Tomes (1979, 1986) developed general equilibrium models of income distribution across family generations. Becker and Tomes $(1979,1175)$ choose a linear tax structure and use revenues for redistribution. They find that "even a progressive tax and public expenditure system may widen the inequality of disposable income." Becker and Tomes (1986, 533-4) note that some empirical work by Arthur Goldberger found that the widening of inequality does not occur for several generations.

May increased government spending and taxation increase both growth and redistribution? Of course, it may, but the empirical data in Alesina and Rodrick (1994) and elsewhere shows that, in developed economies, the reverse is true. Government spending is mainly for redistribution to augment consumption.

In our model, growth of labor productivity and labor income - learning by doing - is a large factor, the largest, in explaining growth of output and living standards. We do not challenge the role of capital or the implication that the return to capital changes very little. The return to labor changes much more. We do not impose our ideas of the desirable extent of income distribution. The workers in our model are voters who choose their preferred tax rate and redistribution. They are aware that an increased tax rate to finance redistribution lowers investment in productivity enhancing investments that add to their future consumption.

Our analysis fits the contours of growth experience. As workers learn, their skills, productivity and incomes increase. They save more, acquire real assets especially housing. They spend to educate their offspring, and they vote for or against redistribution and taxation. In our earlier work,Meltzer and Richard (1981), we showed that rational voters choose a tax rate consistent with the most basic economic theory. They decide whether they want increased taxes to finance more redistribution (consumption today), or lower tax rates to spur investment and future consumption. In the growth model here, the same choice remains 
central.

\section{The Economic Model}

We begin by specifying consumers' endowments. Consumers are infinite-lived and are endowed with different relative levels of productivity at time $t=0$, indexed by $n$, which is lognormally distributed: $\ln (n) \sim \Phi$ where $\Phi$ is the standard cumulative normal distribution function. Exogenenous changes in technology, such as the computerization of production experienced in developed economies during the past 40 years, causes changes in the distribution of relative productivity over time. We use the state variable $s_{t}$ to determine the level of exogenous technological change. A consumer with productivity $n$ at $t=0$ has relative productivity $n^{s_{t}}$ at time $t$; if $s_{t}>1$ the dispersion of relative productivity increases and if $s_{t}<1$ the dispersion decrease. Notice that the distribution of relative productivity is always lognormal because $\ln \left(n^{s_{t}}\right)=s_{t} \ln (n) \sim \Phi\left(0, s_{t}^{2}\right)$. Hence the median relative productivity is fixed for all time at $e^{0}=1$, but mean relative productivity, $\bar{n}_{t}=e^{\frac{1}{2} s_{t}^{2}}>1$, changes as $s_{t}$ changes. Besides productivity each consumer is endowed with one unit of time at all $t$. Each consumer must continuously allocate his one unit of time to labor, $\ell_{t}(n)$, or leisure, $1-\ell_{t}(n)$.

At time $t$, the labor market pays a wage $w_{t}$ per unit of productivity-adjusted labor, so labor income is $w_{t} n^{s_{t}} \ell_{t}(n)$ for a consumer with productivity $n$. Equivalently, $w_{t} n^{s_{t}}$ is the absolute productivity of a consumer with relative productivity $n$ at time $t$. Hence the median relative productivity worker with $n=1$ experiences rising absolute productivity $w_{t}$. The growth of the wage rate, $w_{t}$, is endogenous and due to a learning-by-doing technology. Let $L_{t}$ be the average number of productivity units worked at time $t$ :

$$
L_{t}=\int_{0}^{\infty} \frac{n^{s_{t}} \ell_{t}(n) \exp \left(-\frac{1}{2}(\ln n)^{2}\right)}{n \sqrt{2 \pi}} d n .
$$

Then wage growth is proportional to $L_{t}$ :

$$
\frac{d w_{t}}{d t}=g_{t} L_{t} w_{t},
$$

where $g_{t}$ is an exogenous growth productivity factor.

The level of the growth productivity factor $g_{t}$ is exogenous, determined by the business cycle, with dynamics given by

$$
\frac{d g_{t}}{d t}=\theta\left(s_{t}, g_{t}, t\right) .
$$

The technology dispersion state variable has dynamics

$$
\frac{d s_{t}}{d t}=\mu\left(s_{t}, g_{t}, t\right) .
$$


Taken together equations (2), (3) and (4) describe the evolution of the state of the economy where $x_{t}=\left(s_{t}, w_{t}, g_{t}\right)$ are the state variables.

There is a government which levies a linear tax on income at rate $\tau_{t}$ at time $t$ and uses the proceeds for redistribution, $w_{t} \rho_{t}$, equally per capita. The government's budget is balanced so

$$
\rho_{t}=\tau_{t} L_{t}
$$

The government's choice of tax rate determines the disincentive to work, which, in turn, determines the rate of learning-by doing and the growth rate of the economy. We assume that the tax rate is a function only of the state of the economy:

$$
\tau_{t}=\tau\left(x_{t}\right) .
$$

We now return to consumer welfare maximization. Since there is no capital or other means of saving, everyone continuously consumes their entire income. Hence a consumer with productivity $n$ consumes

$$
c_{t}(n)=\rho_{t} w_{t}+\left(1-\tau_{t}\right) w_{t} n^{s_{t}} \ell_{t}(n),
$$

where $\rho_{t} w_{t}$ is amount of redistribution he receives at time $t$ and $\left(1-\tau_{t}\right) w_{t} n^{s_{t}} \ell_{t}(n)$ is his after-tax labor income at time $t$. A consumer with relative lifetime productivity $n$ maximizes his lifetime utility of consumption and leisure which we assume to be time additive and logarithmic in consumption and leisure:

$$
V^{n}\left(x_{t}, t ; \tau\right)=\max _{\ell(n)} \int_{t}^{\infty} e^{-\delta u}\left[\alpha \ln \left(c_{u}(n)\right)+(1-\alpha) \ln \left(1-\ell_{u}(n)\right)\right] d u,
$$

where, $\alpha \in(0,1), \ell_{t}(n)$ is his labor decision at time $t, c_{t}(n)$, given by equation(7), is his consumption at time $t$, and $\delta$ is the discount rate. The discounted lifetime utility value, $V^{n}\left(x_{t}, t ; \tau\right)$ is conditioned on the tax function $\tau$, which we have not yet specified. Each individual is a price taker in the labor market, takes as given (A) the state processes for $x_{t}$ shown in equations (2), (3), and (4), (B) the tax function equation (6), and (C) redistribution, equation(5), and chooses $\left\{\ell_{t}(n)\right\}$ to maximize utility. The standard Bellman equation for optimal control is

$$
\begin{aligned}
0= & \max _{\ell_{t}(n)}\left\{e^{-\delta t}\left[\alpha \ln \left(c_{t}(n)\right)+(1-\alpha) \ln \left(1-\ell_{t}(n)\right)\right]\right. \\
& \left.+\delta V_{t}^{n}+V_{s}^{n} \mu_{t}\left(s_{t}, g_{t}, t\right)+V_{w}^{n} g_{t} w_{t} L_{t}+V_{g}^{n} \theta_{t}\left(s_{t}, g_{t}, t\right)\right\} .
\end{aligned}
$$

Substituting equation (7) into equation (9) and differentiating by $\ell_{t}(n)$,yields the standard first-order condition:

$$
\ell_{t}(n)=\alpha-\frac{\rho_{t}(1-\alpha)}{n^{s_{t}}\left(1-\tau_{t}\right)}
$$

The maximum fraction of time devoted to working is $\alpha$, as can be seen by setting $\rho_{t}=0$ in equation (10). Since labor must be positive there is a minimum level 
of relative productivity, $\nu_{t}$, below which consumers are voluntarily unemployed, living on their redistribution:

$$
\nu_{t}=\left[\frac{\rho_{t}(1-\alpha)}{\alpha\left(1-\tau_{t}\right)}\right]^{1 / s_{t}} .
$$

We call $\nu_{t}$ the voluntary unemployment productivity. ${ }^{4}$ Optimal consumption is

$$
\begin{aligned}
c_{t}(n) & =\rho_{t} w_{t}, \text { for } n<\nu_{t} . \\
& =\alpha\left(\rho_{t}+\left(1-\tau_{t}\right) n^{s_{t}}\right) w_{t}, \text { for } n \geq \nu_{t} .
\end{aligned}
$$

Notice that for all states $x_{t}$, and hence all choices of $\rho_{t}$ and $\tau_{t}$, that consumption is increasing in $n$ for those who work:

$$
\begin{aligned}
c_{t}^{\prime}(n) & =0, \text { for } n<\nu_{t} . \\
& =\alpha\left(1-\tau_{t}\right) s_{t} n^{s_{t}-1} w_{t}>0, \text { for } n \geq \nu_{t} .
\end{aligned}
$$

Later we exploit equations (13) to establish that the median voter is decisive in continuous elections determining the tax rate.

It is important to note that the time-separable logarithmic utility function causes consumers to make optimal myopic decisions in the dynamic economy. By myopic we mean that it is optimal for each consumer to condition his labor/leisure decision on the current level of wages, taxes, redistribution and relative productivity, and not on any past or future levels of the economy, in order to allocate optimally his time to labor or leisure. Equations (10) and (12) show that each consumer's optimal choice of labor and thus consumption depends only on the current level of wages, $w_{t}$, taxes, $\tau_{t}$, redistribution, $\rho_{t}$, and relative productivity, $n^{s_{t}}$. Consumers recognize that as the state of the economy changes, so do wages, taxes, redistribution and relative productivity, but their choice of labor hours worked at time $t$ does not depend on their past experience or on how they see the future evolving.

Prior to determining how the tax rate is set, we first show that selecting $\nu_{t}$ is an equivalent to selecting $\tau_{t}$. First the optimal average hours worked, $L_{t}$, can be found by substituting equations (10) and (11) into equation (1):

$$
\begin{aligned}
L_{t} & =\int_{\nu_{t}}^{\infty} \frac{\alpha\left(n^{s_{t}}-\nu_{t}^{s_{t}}\right) \exp \left(-\frac{1}{2}(\ln n)^{2}\right)}{n \sqrt{2 \pi}} d n \\
L_{t}\left(\nu_{t}, s_{t}\right) & =\alpha\left[\bar{n}_{t} \Phi\left(-\ln \nu_{t}+s_{t}\right)-\nu_{t}^{s_{t}} \Phi\left(-\ln \nu_{t}\right)\right] .
\end{aligned}
$$

It is obvious from equation (14) that $L_{t}$ is a function only of $s_{t}$ and $\nu_{t}$. Later we need the partial derivatives of $L_{t}\left(\nu_{t}, s_{t}\right)$ with respect to $\nu_{t}$ and $s_{t}$ :

$$
\frac{\partial L_{t}}{\partial \nu_{t}}=-\alpha s_{t} \nu_{t}^{s_{t}-1} \Phi\left(-\ln \nu_{t}\right)<0
$$

\footnotetext{
${ }^{4}$ Of course, outside our model there can be additional involuntary unemployment.
} 
and

$$
\frac{\partial L_{t}}{\partial s_{t}}=\alpha\left[s_{t} \bar{n}_{t} \Phi\left(-\ln \nu_{t}+s_{t}\right)+\bar{n}_{t} \phi\left(-\ln \nu_{t}+s_{t}\right)-\left(\ln \nu_{t}\right) \nu_{t}^{s_{t}} \Phi\left(-\ln \nu_{t}\right)\right]>0,{ }^{5}
$$

where $\phi$ is the unit normal density function. Substituting equation (5) for $\rho_{t}$ into equation (11) and then solving for $\tau_{t}$ gives:

$$
\tau_{t}=\frac{\alpha \nu_{t}^{s_{t}}}{\alpha \nu_{t}^{s_{t}}+(1-\alpha) L_{t}} .
$$

So $\tau_{t}$ is completely determined by the state variables $x_{t}$ and $\nu_{t}$. In fact, given the state variables $x_{t}$, the relationship between $\tau_{t}$ and $\nu_{t}$ is one-to-one as can be seen by showing that $\tau_{t}$ is a strictly increasing function of $\nu_{t}$ :

$$
\frac{d \tau_{t}}{d \nu_{t}}=\frac{\alpha^{2}(1-\alpha) s_{t} \nu_{t}^{s_{t}-1} \bar{n}_{t} \Phi\left(-\ln \nu_{t}+s_{t}\right)}{\left(\alpha \nu_{t}^{s_{t}}+(1-\alpha) L_{t}\right)^{2}}>0 .
$$

Hence the mapping from $\nu_{t}$ to $\tau_{t}$ is continuous and strictly increasing, so that setting $\nu_{t}$ is equivalent to setting $\tau_{t}$.

Armed with he fact that setting $\nu_{t}$ is equivalent to setting $\tau_{t}$, we determine redistribution, $\rho_{t}$, labor, $\ell_{t}(n)$, and consumption, $c_{t}(n)$ as functions of $\nu_{t}$ and the states, $x_{t}$. Substituting equation (17) into equation (5) gives:

$$
\rho_{t}=\frac{\alpha \nu_{t}^{s_{t}} L_{t}}{\alpha \nu_{t}^{s_{t}}+(1-\alpha) L_{t}} .
$$

Substituting equation (11) into equation (10) we find that

$$
\ell_{t}(n)=\alpha\left(1-\frac{\nu_{t}^{s_{t}}}{n^{s_{t}}}\right) \text {. }
$$

Finally, substituting equations (20), (17), and (19) into equation (12) gives:

$$
\begin{aligned}
c_{t}(n) & =\alpha w_{t} L_{t} \frac{\nu_{t}^{s_{t}}}{\alpha \nu_{t}^{s_{t}}+(1-\alpha) L_{t}}, \text { for } n<\nu_{t} . \\
& =\alpha w_{t} L_{t} \frac{\alpha \nu_{t}^{s_{t}}+(1-\alpha) n^{s_{t}}}{\alpha \nu_{t}^{s_{t}}+(1-\alpha) L_{t}}, \text { for } n \geq \nu_{t} .
\end{aligned}
$$

Hence everything in this economy is a function of the state variables, $x_{t}$, and $\nu_{t}$.

Lastly, we determine the mean number of unadjusted labor units worked per capita, $\bar{\ell}_{t}$ :

$$
\begin{aligned}
\bar{\ell}_{t} & =\int_{\nu_{t}}^{\infty} \frac{\ell_{t}(n) \exp \left(-\frac{1}{2}(\ln n)^{2}\right)}{n \sqrt{2 \pi}} d n \\
& =\int_{\nu_{t}}^{\infty} \frac{\alpha\left(1-\nu_{t}^{s_{t}} / n^{s_{t}}\right) \exp \left(-\frac{1}{2}(\ln n)^{2}\right)}{n \sqrt{2 \pi}} d n \\
& =\alpha\left[\Phi\left(-\ln \nu_{t}\right)-\nu_{t}^{s_{t}} \bar{n}_{t} \Phi\left(-\ln \nu_{t}-s_{t}\right)\right] .
\end{aligned}
$$

\footnotetext{
${ }^{5}$ Recall that $\nu_{t}<1$ so that $-\ln \left(\nu_{t}\right)>0$.
} 
Hence, the fraction of full time labor worked per capita at time $t$ is $\bar{\ell}_{t} / \alpha$ and the fraction of full time labor worked per employed person, $\bar{L}_{t}$, is

$$
\bar{L}_{t}=1-\frac{\nu_{t}^{s_{t}} \bar{n}_{t} \Phi\left(-\ln \nu_{t}-s_{t}\right)}{\Phi\left(-\ln \nu_{t}\right)} .
$$

\section{The Distribution of Pre-Tax Income and After- Tax Consumption}

We can now show that regardless of how tax rates are determined, the distribution of pre-tax income widens as taxes rise. This widening has nothing to do with technological change or the privileges of the rich. The widening of the distribution of income is the direct consequence of the incentives created by increasing taxes and redistribution. The pre-tax income of a consumer with relative productivity $n$ at time $t$ is

$$
\begin{aligned}
I_{t}(n) & =0 \text { for } n<\nu_{t}, \\
& =w_{t} n^{s_{t}} \ell_{t}(n) \text { for } n \geq \nu_{t} .
\end{aligned}
$$

Substituting equation (20) into equation (26) gives

$$
\begin{aligned}
I_{t}(n) & =0 \text { for } n<\nu_{t}, \\
& =w_{t} \alpha\left(n^{s_{t}}-\nu_{t}^{s_{t}}\right) \text { for } n \geq \nu_{t} .
\end{aligned}
$$

Assuming that he works, the median consumer's income is

$$
I_{t}(1)=w_{t} \alpha\left(1-\nu_{t}^{s_{t}}\right) .
$$

In equilibrium, the average pre-tax income of all consumers, both those who work and those who live on redistribution, is

$$
\bar{I}_{t}=w_{t} L_{t} .
$$

Higher taxes causes the average income of all consumers (which in equilibrium must equal the average consumption of all consumers) to fall:

$$
\frac{\partial \bar{I}_{t}}{\partial \nu_{t}}=-w_{t} \alpha s_{t} \nu_{t}^{s_{t}-1} \Phi\left(-\ln \nu_{t}\right)<0,
$$

where we have used equation (15) for $\frac{\partial L_{t}}{\partial \nu_{t}}$.

A commonly used measure of the dispersion of income is the ratio of mean to median income:

$$
r_{t}=\frac{\bar{I}_{t}}{I_{t}(1)}=\frac{L_{t}}{\alpha\left(1-\nu_{t}^{s_{t}}\right)} .
$$

Differentiating with respect to $\nu_{t}$, we get that

$$
\frac{d r_{t}}{d \nu_{t}}=\frac{s_{t} \nu_{t}^{s_{t}-1}\left[\bar{n}_{t} N\left(-\ln \nu_{t}+s_{t}\right)-N\left(-\ln \nu_{t}\right)\right]}{\left(1-\nu_{t}^{s_{t}}\right)^{2}}>0 .
$$


so that the ratio of mean to median income rises as tax rates increase. In fact all consumers with productivity above (below) median increase (reduce) their income relative to median income as taxes rise:

$$
\begin{aligned}
\frac{d\left(I_{t}(n) / I_{t}(1)\right)}{d \nu_{t}} & =0 \text { for } n<\nu_{t} \\
& =\frac{s_{t} \nu_{t}^{s_{t}-1}\left(n^{s_{t}}-1\right)}{\left(1-\nu_{t}^{s_{t}}\right)^{2}} \text { for } n \geq \nu_{t}
\end{aligned}
$$

Another commonly used measure of the dispersion of pre-tax income is the fraction earned by the top $k \%$. The upper $k \%$ begins with the consumer with relative productivity

$$
n^{*}(k)=\exp \left(-\Phi^{-1}(k)\right) .
$$

For example, the upper $1 \%$ begins with relative productivity $n^{*}(0.01)=\exp \left(-\Phi^{-1}(0.01)\right)$ or $n^{*}(0.01) \approx e^{2.33}$ and the top $10 \%$ begins with productivity $n^{*}(0.1) \approx e^{1.28}$. Let $P$ denote the total population so that $\phi(n) P$ equals the number of consumers with relative productivity $n$. The total income of the top $k \%$ of consumers is

$$
\begin{aligned}
\widetilde{I}_{t}(k) & =P \alpha w_{t} \int_{n^{*}(k)}^{\infty}\left(n^{s_{t}}-\nu_{t}^{s_{t}}\right) \frac{\exp \left(-\frac{1}{2}(\ln n)^{2}\right)}{\sqrt{2 \pi} n} d n \\
& =P \alpha w_{t}\left[\bar{n}_{t} \Phi\left(-\ln n^{*}(k)+s_{t}\right)-\nu_{t}^{s_{t}} k\right] .
\end{aligned}
$$

The fraction of pre-tax income earned by the top $k \%$ is

$$
\psi_{t}(k)=\frac{\widetilde{I}_{t}(k)}{P \bar{I}_{t}}=\frac{\bar{n}_{t} \Phi\left(-\ln n^{*}(k)+s_{t}\right)-\nu_{t}^{s_{t}} k}{\bar{n}_{t} \Phi\left(-\ln \nu_{t}+s_{t}\right)-\nu_{t}^{s_{t}} \Phi\left(-\ln \nu_{t}\right)} .
$$

Differentiating $\psi_{t}(k)$ with respect to $\nu_{t}$ shows that

$\frac{\psi_{t}(k)}{d \nu_{t}}=\frac{s_{t} \nu_{t}^{s_{t}-1} \bar{n}_{t} k \Phi\left(-\ln \nu_{t}\right)}{\left(\bar{n}_{t} \Phi\left(-\ln \nu_{t}+s_{t}\right)-\nu_{t}^{s_{t}} \Phi\left(-\ln \nu_{t}\right)\right)^{2}}\left[\frac{\Phi\left(-\ln n^{*}(k)+s_{t}\right)}{\Phi\left(-\ln n^{*}(k)\right)}-\frac{\Phi\left(-\ln \nu_{t}+s_{t}\right)}{\Phi\left(-\ln \nu_{t}\right)}\right]>0$,

which is positive for $n^{*}(k)>\nu_{t}$. Hence as taxes rise so does the income share of the top $k \%$.

The number of consumers in the top $k \%$ is $P k$, so per capita income in the top $k \%$ is

$$
\widehat{I}_{t}(k)=\frac{\widetilde{I}_{t}(k)}{P k}=\frac{\alpha w_{t}\left[\bar{n}_{t} \Phi\left(-\ln n^{*}(k)+s_{t}\right)-\nu k\right]}{k}
$$

Hence the ratio of per capita income of consumers in the top $k \%$ relative to median pre-tax income is

$$
\frac{\widehat{I}_{t}(k)}{I_{t}(1)}=\frac{\bar{n}_{t} \Phi\left(-\ln n^{*}(k)+s_{t}\right)-\nu_{t}^{s_{t}} k}{\left(1-\nu_{t}^{s_{t}}\right) k}
$$

Differentiating equation (39) with respect to $\nu_{t}$ shows that:

$$
\frac{d\left(\widehat{I}_{t}(k) / I_{t}(1)\right)}{d \nu_{t}}=s_{t} \nu_{t}^{s_{t}-1} \frac{\bar{n}_{t} \Phi\left(-\ln n^{*}(k)+s_{t}\right)-k}{k\left(1-\nu_{t}^{s_{t}}\right)^{2}}>0 .
$$


Again, "the rich get richer" relative to the median as taxes rise. Again, this is an inevitable consequence of taxation and redistribution.

There is much discussion in the media, and even among academics, of how rising income dispersion is evidence of a more "unequal" society. This is, of course, very misleading because funds collected in taxes are redistributed so that the distribution of consumption actually narrows with increased taxes. The welfare implication of increased taxation is a more equal, "fair" society, despite an increase in the dispersion of pre-tax incomes. Using equation (21) we calculate the ratio of consumption of a consumer with relative productivity $n$ to the median consumption:

$$
\begin{aligned}
\frac{c_{t}(n)}{c_{t}(1)} & =\frac{\nu_{t}^{s_{t}}}{\alpha \nu_{t}^{s_{t}}+1-\alpha} \text { for } n<\nu_{t}, \\
& =\frac{\alpha \nu_{t}^{s_{t}}+(1-\alpha) n^{s_{t}}}{\alpha \nu_{t}^{s_{t}}+1-\alpha} \text { for } n \geq \nu_{t}
\end{aligned}
$$

In fact all consumers with productivity above (below) median reduce (increase) their consumption relative to median consumption as taxes rise:

$$
\begin{aligned}
\frac{d\left(c_{t}(n) / c_{t}(1)\right)}{d \nu_{t}} & =\frac{(1-\alpha) s_{t} \nu_{t}^{s_{t}-1}}{\left(\alpha \nu_{t}^{s_{t}}+1-\alpha\right)^{2}}>0 \text { for } n<\nu_{t}, \\
& =\frac{\alpha(1-\alpha) s_{t} \nu_{t}^{s_{t}-1}\left(1-n^{s_{t}}\right)}{\left(\alpha \nu_{t}^{s_{t}}+1-\alpha\right)^{2}} \text { for } n \geq \nu_{t}
\end{aligned}
$$

What about the top $k \%$ ? The per capita consumption of the top $k \%$ is

$$
\widehat{c}_{t}(k)=\alpha w_{t} L_{t} \frac{\alpha \nu_{t}^{s_{t}} \Phi\left(-\ln n^{*}(k)\right)+(1-\alpha) \bar{n}_{t} \Phi\left(-\ln n^{*}(k)+s_{t}\right)}{k\left(\alpha \nu_{t}^{s_{t}}+(1-\alpha) L_{t}\right)}
$$

The per capita consumption of the top $k \%$ falls relative to median consumption as taxes increase:

$$
\frac{d\left(\widehat{c}_{t}(k) / c_{t}(1)\right)}{d \nu_{t}}=-\frac{\alpha(1-\alpha) s_{t} \nu_{t}^{s_{t}-1}\left(\bar{n}_{t} \Phi\left(-\ln n^{*}(k)+s_{t}\right)-\Phi\left(-\ln n^{*}(k)\right)\right)}{k\left(\alpha \nu_{t}^{s_{t}}+1-\alpha\right)^{2}}<0
$$

\section{The Median Voter}

Until now all consumer have been price takers who have no influence over government tax policy. Romer (1975) and Roberts (1977) shows that if the ordering of individual consumption is increasing in $n$, for any choice of $\rho_{t}$ and $\tau_{t}$, then the median voter is decisive in a majority rule election to set the tax rate. ${ }^{6}$ We have already shown in equation (13) that for any choice of $\rho_{t}$ and $\tau_{t}$, consumption is

\footnotetext{
${ }^{6}$ Roberts (2015) extends his work on majority rules to clubs. In a club, the membership is endogenous because current members choose the new members in majority rules elections.
} 
strictly increasing in $n$ for those who work. So the median voter is continuously decisive in elections for $\left\{\tau_{t}\right\}$.

We now turn to analyzing how the median voter would prefer to set tax rates. The median voter's lifetime utility maximization problem is now

$$
V\left(x_{t}, t\right)=\max _{\left\{\tau_{u}, \ell_{u}\right\}} \int_{t}^{\infty} e^{-\delta u}\left[\alpha \ln \left(c_{u}(1)\right)+(1-\alpha) \ln \left(1-\ell_{u}(1)\right)\right] d u,
$$

where we have suppressed the superscript $V^{1}$. The standard Bellman equation for optimal control is revised to

$$
\begin{aligned}
& 0 \underset{\left\{\tau_{t}, \ell_{t}\right\}}{\max }\left\{e^{-\delta t}\left[\alpha \ln \left(c_{t}(1)\right)\right)+(1-\alpha) \ln \left(1-\ell_{t}(1)\right)\right] \\
& \left.+V_{t}+V_{s} \mu\left(s_{t}, g_{t}, t\right)+V_{w} g_{t} w_{t} L_{t}+V_{g} \theta\left(s_{t}, g_{t}, t\right)\right\}
\end{aligned}
$$

We can simplify equation (47) by defining

$$
V\left(x_{t}, t\right)=e^{-\delta t} J\left(x_{t}, t\right),
$$

which we substitute into equation (47) to find

$$
\begin{aligned}
0= & \max _{\left\{\tau_{t}, \ell_{t}\right\}}\left\{\alpha \ln \left(c_{t}(1)\right)\right)+(1-\alpha) \ln \left(1-\ell_{t}(1)\right) \\
& \left.-\delta J+J_{t}+J_{s} \mu\left(s_{t}, g_{t}, t\right)+J_{w} g_{t} w_{t} L_{t}+J_{g} \theta\left(s_{t}, g_{t}, t\right)\right\}
\end{aligned}
$$

Substituting equation (21) evaluated at $n=1$ for the median voter's optimal consumption and equation (20) evaluated at $n=1$ for the median voter's optimal labor into equation (49) we find

$$
\begin{aligned}
0= & \max _{\tau_{t}}\left\{\alpha \ln \alpha+\alpha \ln w_{t}+\alpha \ln L_{t}+\ln \left(\alpha \nu_{t}^{s_{t}}+1-\alpha\right)-\alpha \ln \left(\alpha \nu_{t}^{s_{t}}+(1-\alpha) L_{t}\right)\right. \\
& \left.-\delta J+J_{t}+J_{s} \mu\left(s_{t}, g_{t}, t\right)+J_{w} w_{t} L_{t} g_{t}+J_{g} \theta\left(s_{t}, g_{t}, t\right)\right\} .
\end{aligned}
$$

We now make a substitution of variables to make analyzing the model easier. Let $z_{t}$ denote the dispersion-adjusted voluntary unemployment productivity

$$
z_{t}=\nu_{t}^{s_{t}} .
$$

In terms of $z_{t}$, aggregate hours worked is

$$
L_{t}\left(z_{t}, s_{t}\right)=\alpha\left[\bar{n}_{t} \Phi\left(\frac{-\ln z_{t}}{s_{t}}+s_{t}\right)-z_{t} \Phi\left(-\frac{\ln z_{t}}{s_{t}}\right)\right] .
$$

The partial derivatives of $L_{t}\left(z_{t}, s_{t}\right)$ are

$$
\frac{\partial L_{t}\left(z_{t}, s_{t}\right)}{\partial z_{t}}=-\alpha \Phi\left(-\frac{\ln z_{t}}{s_{t}}\right)<0
$$

and

$$
\frac{\partial L_{t}\left(z_{t}, s_{t}\right)}{\partial s_{t}}=\alpha s_{t} \bar{n}_{t} \Phi\left(\frac{-\ln z_{t}}{s_{t}}+s_{t}\right)+\alpha z_{t} \phi\left(-\frac{\ln z_{t}}{s_{t}}\right)>0 .
$$


In terms of $z_{t}$, the tax rate is

$$
\tau_{t}=\frac{\alpha z_{t}}{\alpha z_{t}+(1-\alpha) L_{t}\left(z_{t}, s_{t}\right)}
$$

so that

$$
\frac{d \tau_{t}}{d z_{t}}=\alpha^{2}(1-\alpha) \frac{\bar{n}_{t} \Phi\left(\frac{-\ln z_{t}}{s_{t}}+s_{t}\right)}{\left(\alpha z_{t}+(1-\alpha) L_{t}\left(z_{t}, s_{t}\right)\right)^{2}}>0 .
$$

We see from equations (55) and (56) that voting for $z_{t}$ is equivalent to voting for $\tau_{t}$ given the states $x_{t}$. Substituting equation (51) into equation (50) gives

$$
\begin{aligned}
0= & \max _{z_{t}}\left\{\alpha \ln \alpha+\alpha \ln w_{t}+\alpha \ln L_{t}\left(z_{t}, s_{t}\right)+\ln \left(\alpha z_{t}+1-\alpha\right)-\alpha \ln \left(\alpha z_{t}+(1-\alpha) L_{t}\left(z_{t}, s_{t}\right)\right)\right. \\
& \left.-\delta J+J_{t}+J_{s} \mu\left(s_{t}, g_{t}, t\right)+J_{w} w_{t} g_{t} L_{t}\left(z_{t}, s_{t}\right)+J_{g} \theta\left(s_{t}, g_{t}, t\right)\right\} .
\end{aligned}
$$

We try the solution

$$
J\left(x_{t}, t\right)=\frac{\alpha}{\delta} \ln w_{t}+j\left(g_{t}, s_{t}, t\right) .
$$

Substituting equation (58) into equation (57) gives

$$
\begin{aligned}
0= & \max _{z_{t}}\left\{\alpha \ln \alpha+\alpha \ln L_{t}+\ln \left(\alpha z_{t}+1-\alpha\right)-\alpha \ln \left(\alpha z_{t}+(1-\alpha) L_{t}\right)\right. \\
& \left.-\delta j+j_{t}+j_{s} \mu\left(s_{t}, g_{t}, t\right)+g_{t} \frac{\alpha}{\delta} L_{t}+j_{g} \theta\left(s_{t}, g_{t}, t\right)\right\} .
\end{aligned}
$$

Using equation (53) we calculate the derivative with respect to $z_{t}$ of the righthand-side of equation (59) as

$H\left(z_{t}, s_{t}, g_{t}\right)=\alpha\left[\frac{-\alpha \Phi\left(-\frac{\ln z_{t}}{s_{t}}\right)}{L_{t}}+\frac{1}{\alpha z_{t}+1-\alpha}-\frac{\alpha\left(1-(1-\alpha) \Phi\left(-\frac{\ln z_{t}}{s_{t}}\right)\right)}{\alpha z_{t}+(1-\alpha) L_{t}}-\frac{\alpha}{\delta} g_{t} \Phi\left(-\frac{\ln z_{t}}{s_{t}}\right)\right]$.

The median voter's choice of $z_{t}$ (and hence of $\left.\tau_{t}\right)$ is that $z_{t}^{*}\left(s_{t}, g_{t}\right)$ which solves the first order condition

$$
H\left(z_{t}^{*}, s_{t}, g_{t}\right)=0
$$

and, we assume, the second order condition

$$
H_{z}\left(z_{t}^{*}, s_{t}, g_{t}\right)<0 .
$$

We cannot solve equation (61) explicitly for $z_{t}^{*}\left(s_{t}, g_{t}\right)$, but instead use equation (61) as an implicit equation for $z_{t}^{*}\left(s_{t}, g_{t}\right)$.

\section{The Size of Government}

We measure the size of government by its tax share. We show that an increase in the growth productivity factor, ceteris paribus, causes the median voter to choose lower taxes. Conversely, an increase in the dispersion of relative productivity, $s_{t}$, ceteris paribus, causes the median voter to choose higher taxes. 
To see this we calculate the signs of the derivatives of $z_{t}^{*}\left(s_{t}, g_{t}\right)$ with respect to the states. First, differentiate equation (61) with respect to $g_{t}$ :

$$
H_{z} \frac{\partial z_{t}^{*}}{\partial g_{t}}-\frac{\alpha^{2}}{\delta} \Phi\left(-\frac{\ln z_{t}}{s_{t}}\right)=0,
$$

which we rearrange to find that

$$
\frac{\partial z_{t}^{*}}{\partial g_{t}}=\frac{\alpha^{2} \Phi\left(-\frac{\ln z_{t}}{s_{t}}\right)}{\delta H_{z}}<0 .
$$

Equation (64) implies that the median voter choose lower $z_{t}^{*}$, which implies lower taxes, when the growth productivity factor increases. Next, we need the partial derivative of $H$ with respect to $s_{t}$ :

$$
\begin{aligned}
H_{s} & =\alpha\left[\frac{\Phi\left(-\frac{\ln z_{t}}{s_{t}}\right)}{L_{t}^{2}}+\frac{(1-\alpha)\left(1-(1-\alpha) \Phi\left(-\frac{\ln z_{t}}{s_{t}}\right)\right)}{\left(z_{t}+(1-\alpha) L_{t}\right)^{2}} \frac{\partial L_{t}}{\partial s_{t}}\right] \\
-\frac{\alpha \phi\left(-\frac{\ln z_{t}}{s_{t}}\right) \ln z_{t}}{s_{t}^{2}}\left[\frac{\alpha z_{t}}{L_{t}\left(z_{t}+(1-\alpha) L_{t}\right)}+\frac{g_{t}}{\delta}\right] & >0 .
\end{aligned}
$$

Assuming the median voter works, $z_{t}<1$ so that $\ln z_{t}<0$, implying that $H_{s}>0$. Taking the derivative of equation (61) with respect to $s_{t}$, we get

$$
H_{z} \frac{\partial z_{t}^{*}}{\partial s_{t}}+H_{s}=0,
$$

which implies that

$$
\frac{\partial z_{t}^{*}}{\partial s_{t}}=-\frac{H_{s}}{H_{z}}>0 .
$$

Equation (67) implies that the median voter choose higher $z_{t}^{*}$, which implies higher taxes, when technology dispersion increases.

\section{Economic Growth}

Armed with the median's voter's choice of the tax rate, we can calculate the effect of taxes on growth. The growth rate of the economy at time $t$, denoted $\gamma_{t}$, equals the growth rate of average income, which is given by equation(29).

$$
\begin{aligned}
\gamma_{t} & =\frac{1}{\bar{I}_{t}} \frac{d \bar{I}_{t}}{d t} \\
& =\frac{1}{w_{t}} \frac{d w_{t}}{d t}+\frac{1}{L_{t}\left(s_{t}, g_{t}\right)} \frac{d L_{t}\left(z_{t}^{*}\left(s_{t}, g_{t}\right), s_{t}\right)}{d t} \\
& =g_{t} L_{t}+\frac{1}{L_{t}}\left[\frac{\partial L_{t}}{\partial s_{t}}+\frac{\partial L_{t}}{\partial z_{t}^{*}} \frac{\partial z_{t}^{*}}{\partial s_{t}}\right] \mu\left(s_{t}, g_{t}, t\right)+\frac{1}{L_{t}} \frac{\partial L_{t}}{\partial z_{t}^{*}} \frac{\partial z_{t}^{*}}{\partial g_{t}} \theta\left(s_{t}, g_{t}, t\right) .(68)
\end{aligned}
$$

There are three effects on economic growth captured in equation (68). The first term, $g_{t} L_{t}$, is the growth rate due to current learning by doing, which is 
smaller the higher are taxes since $\frac{d L_{t}}{d z_{t}^{*}}<0$. The second term captures the effect of changes in the dispersion of relative productivity on growth. The effect of an increase in dispersion, $s_{t}$, on the growth rate of the economy is ambiguous since the bracketed term in equation (68) is of indeterminate sign because $\frac{\partial L_{t}}{\partial s_{t}}$, which is the direct effect of $s_{t}$ on aggregate labor, is always positive, but $\frac{\partial L_{t}}{\partial z_{t}^{*}} \frac{\partial z_{t}^{*}}{\partial s_{t}}$, which is the indirect effect of increasing taxes, is negative. The third term is positive whenever learning-by-doing productivity is increasing, $\theta\left(s_{t}, g_{t}, t\right)>0$; in this case the economy grows faster because both $\frac{\partial L_{t}}{\partial z_{t}^{*}}<0$ and $\frac{\partial z_{t}^{*}}{\partial g_{t}}<0$.

\section{Calibration}

We now calibrate our model. Our model has four calculated outputs for which we have be able to find empirical analogues:

1. The growth rate of the economy, $\gamma_{t}$, which is calculated using equation (68).

2. The fraction of full time labor per employed person, $\bar{L}_{t}$, which is calculated using equation (25).

3. A measure of income dispersion. Either

(a) The ratio of mean to median income, $r_{t}$, which is calculated using equation (31), or

(b) The fraction of income earned by the top $10 \%, \psi_{t}(0.1)$, calculated using equation $(36){ }^{7}$

4. The tax rate, $\tau_{t}$, which is calculated using equation (17).

The empirical analogues we found are

1. Real annual growth rate of per capita GDP, denoted $\Gamma_{t}$.

2. The average annual hours worked per engaged person divided by the annual hours comprising full time employment, $F$; the ratio is denoted $\Lambda_{t}$.

3. Either

(a) The ratio of mean to median annual household income, denoted $R_{t}$; or

(b) The annual income share of the top $10 \%$ taken from the The World Top Income Database, denoted $\Psi_{t}$.

\footnotetext{
${ }^{7}$ We think that the household income data is likely to be better measured because it is based on a census bureau survey of the US population or the ONS survey in the UK. In contrast, the income fraction of the top $10 \%$ is taken from income tax returns. Changes in tax laws and non-compliance means the tax data are not necessarily a consistent sample from year to year.
} 


\section{Annual total government expenditures as a fraction of GDP, $T_{t}{ }^{8}$}

We calibrate the model using data from three countries, the US, the UK and France. These are the only countries where we have been able to find the required data over a reasonably long time period. US data is drawn from two overlapping periods: from 1967 to 2011, during which time the Census Bureau has calculated mean to median annual household income; and a longer time period from 1950 to 2011 for which we have the income share of the top $10 \%$. Similarly, for the UK we draw data from two overlapping periods: from 1977 to 2011, during which time the Office of National Statistics has calculated mean to median annual household income ${ }^{9}$; and a longer time period from 1962 to 2011 for which we have the income share of the top $10 \%{ }^{10}$ In France we use data for the annual income share of the top $10 \%$ from $1978-2009 .{ }^{11}$ The choice of estimation periods reflects the first and last dates when the necessary data are available. $^{12}$ Our data sources are in Table 2.

$\begin{array}{rrrr} & \text { France } & \text { UK } & \text { US } \\ \text { Real GDP per Capita Growth Rate } & \text { INSEE } & \text { MW } & \text { FRED } \\ \text { Productivity Index (TFP) } & \text { FRED } & \text { FRED } & \text { FRED } \\ \text { Mean Ann. Hours per Engaged Person } & \text { FRED } & \text { FRED } & \text { FRED } \\ \text { Mean \& Median Household Income } & \text { EuroStat } & \text { ONS } & \text { CB } \\ \text { Government Expenditures/GDP } & \text { EuroStat } & \text { UPS } & \text { FRED } \\ \text { Income Share of Top 10\% } & \text { WTID } & \text { WTID } & \text { WTID }\end{array}$

Table 2: Data Sources. INSEE is the French National Institute of Statistics and Economic Studies. MW is MeasuringWorth.com. FRED is the Federal Reserve Economic Data at the Federal Reserve Bank of St. Louis. EuroStat is the economic database of the European Commission. ONS is the UK's Office of National Statistics. CB is the US Census Bureau. UPS is UKPublicSpending.co.uk. WTID is the The World Top Incomes Database.

Since our model has no uncertainty, we assume that the difference between the model's output and the analogous data are independent, normallydistributed, measurement errors . Measurement errors are, in fact, likely to be

\footnotetext{
${ }^{8}$ Measuring the effective tax rate as government expenditure/GDP was suggested by Milton Friedman.

${ }^{9}$ Mean and median household income data in the UK are available only after 1977 . Following the European Union standard, the data are adjusted for changing household composition, including the number of people in the household and number of unemployed people. So the UK mean to median household income data is a close, but not perfect, analogue of the US Census Bureau data.

${ }^{10}$ Prior to 1962 , the data for income share of the top $10 \%$ in the UK are spotty.

${ }^{11}$ Data for total French government expenditures begins in 1978. We end in 2009 because that is the last year in which the income share of the top $10 \%$ is reported. Mean and median household income data are only available from 1995 onward, which we think is too short a time period.

${ }^{12}$ Our data is available in an Excel spreadsheet at https://fnce.wharton.upenn.edu/profile/972/. Also available is Matlab code for the calibration.
} 
significant since much of our data is calculated by governments based on surveys of households and industries. Hence we assume that

$$
\varepsilon_{t}=\left[\Gamma_{t}-\gamma_{t}, \Lambda_{t}-\bar{L}_{t}, R_{t}-r_{t}, T_{t}-\tau_{t}\right],{ }^{13}
$$

where $\varepsilon_{i t} \sim \Phi\left(0, \sigma^{2}\right)$ are i.i.d. The log-likelihood function is

$$
\mathcal{L}=\sum_{t=1}^{N}-\frac{1}{2}\left(4 \ln (2 \pi)+4 \ln \left(\sigma^{2}\right)+\varepsilon_{t} \varepsilon_{t}^{\prime} / \sigma^{2}\right) .
$$

For each country (and each time period in the US and the UK), we want to maximize $\mathcal{L}$ by finding the states $\left\{\nu_{t}, s_{t}\right\}$, the taste parameter $\alpha$ and the number of annual hours equivalent to full time labor, $F$. It is well-known that we can maximize the likelihood by minimizing the sum of squared errors

$$
S S E=\sum_{t=1}^{N} \varepsilon_{t} \varepsilon_{t}^{\prime}
$$

and that the maximum likelihood estimator of $\sigma^{2}$ is

$$
\widehat{\sigma}^{2}=\frac{S S E}{4 N} .
$$

Finally, we set the time discounting factor $\delta=4 \%{ }^{14}$

The third state variable which is median productivity, $w_{t}$, is computed from the productivity index, $P_{t}$. We equate average total output calculated by using productivity-adjusted labor, equation (29), with average total output calculated using unadjusted labor:

$$
\bar{I}_{t}=w_{t} L_{t}=P_{t} \bar{\ell}_{t}
$$

Solving equation (73) we get

$$
w_{t}=\frac{P_{t} \bar{\ell}_{t}}{L_{t}}
$$

Unfortunately, because $w_{t}$ does not enter into any consumer's optimal decision making and because there is no reported data on median productivity, we cannot compare our estimated values of $w_{t}$ to any actual data.

We minimize $S S E$ by a numerical search. The search steps are:

1. Make a starting guess for the states, $\left\{\nu_{t}, s_{t}\right\}$, and parameters, $\alpha$ and $F$.

2. For each $t$, solve equation (61) for $g_{t}$.

3. Compute $\gamma_{t}, \bar{\ell}_{t}, r_{t}$ and $\tau_{t}$.

\footnotetext{
${ }^{13}$ If we are using data on the income share of the top $10 \%$, then substitute $\Psi_{t}-\psi_{t}$ for $R_{t}-r_{t}$.

${ }^{14}$ We cannot estimate $\delta$ because it is not identified unless we have observations on the productivity factor $g_{t}$, which is not observable.
} 
4. Compute the sum of squared errors.

5. Update the states, $\left\{\nu_{t}, s_{t}\right\}$, and parameters, $\alpha$ and $F$, using a Nelder-Mead algorithm.

6. Repeat steps (2) - (5) until convergence.

When reporting the results of each of the searches we show a graph with four panels, corresponding to the four comparisons of model to data listed above and a second graph showing the state variables $w_{t}, g_{t}, s_{t}$ and the voluntary unemployment productivity, $\nu_{t}$.

\subsection{The United States}

We estimate our model for the United States over two different time periods. During the first period from 1967 to 2011 we use annual observations on real per capita GDP growth rate, average annual hours worked per engaged person, the ratio of mean to median household income, and the ratio of total government expenditures to GDP. During the second, longer period, from 1950 to 2011, we substitute the income share of the top $10 \%$ for the ratio of mean to median household income which is not available prior to 1967.

\subsubsection{US Mean-to-Median Ratio Data}

We begin with data from the US from 1967 - 2011. Figure 1 shows a comparison of actual data and model calculations. Obviously the fits of the model to the data are excellent. The root-mean-squared-error (RMSE), $\widehat{\sigma}$, is only $1.1 \%$. The $r^{2}$ for the fit of actual data to the model are $54.0 \%, 76.4 \%, 97.9 \%$, and $88.8 \%$, for growth, hours per employed person, mean to median income, and the tax rate, respectively. The downward trend in hours worked per employed person reflects an international trend as we see below. Mean to median income and government expenditures as a fraction of GDP have both trended upward as a result of increased dispersion in relative productivity as shown in Figure 2.

Figure 2 shows the optimal estimated states, $\left\{g_{t}, s_{t}, w_{t}\right\}$, and $\nu_{t}$, from 1967 - 2011. The productivity growth multiplier, shown in Panel 1, increased from 1967, reached a peak in 2000, and declined afterward. The dispersion of relative productivity, shown in Panel 2, increased steadily from 1967 through 2000, but has leveled off since then. Panel 3 shows two productivity indexes. The first is the standard measure of Total Factor Productivity (TFP). In the US TFP started a sharp increase in the early 1980s and has grown steadily thereafter, but with dips for recessions. The second productivity index is the state variable, $w_{t}$, which measures the productivity of the median worker. Median productivity, $w_{t}$, declines slightly until the 1980s, but after that begins a steady upward climb mimicking the rise in TFP. The spread between TFP and median productivity, however, continues to widen throughout. Panel 4 shows that there has been a steady upward trend in the productivity cutoff for voluntary unemployment corresponding to the upward trend in redistribution. 

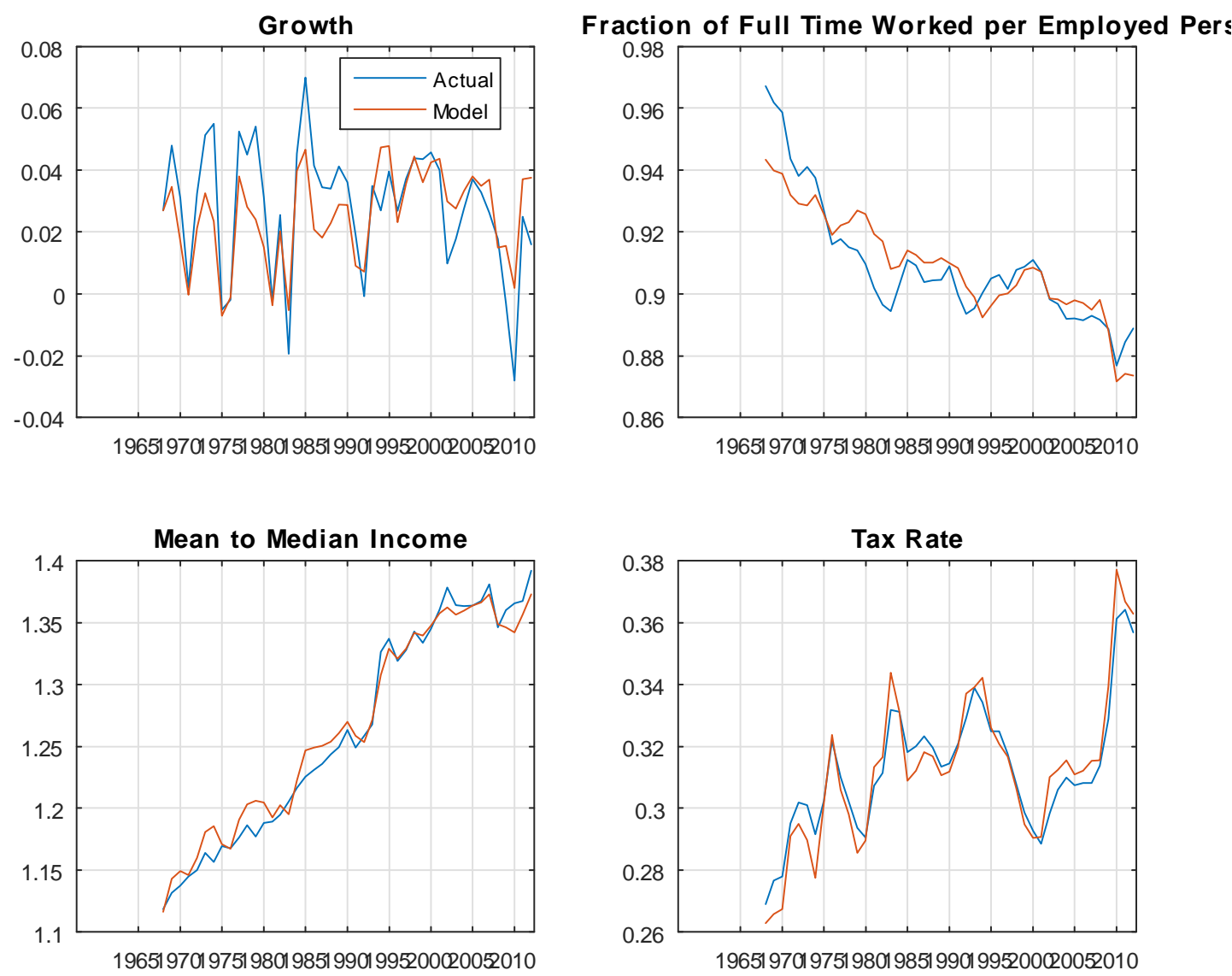

Figure 1: A comparison of actual data and model calculations for the US 1967 - 2011. Panel 1 shows a comparison of the actual rate of real per capita GDP growth to the model's calculated rate of real per capita income growth, $\gamma_{t}$. Panel 2 shows a comparison of the actual average fraction of full time hours worked per engaged person to the model's calculated average fraction of full time worked per employed person, $\bar{L}_{t}$. Panel 3 shows a comparison of the actual ratio of mean to median household income to the model's calculated ratio of mean to median income, $r_{t}$. Panel 4 shows a comparison of the actual ratio of total government expenditures to GDP to the model's linear tax rate, $\tau_{t}$. 
G
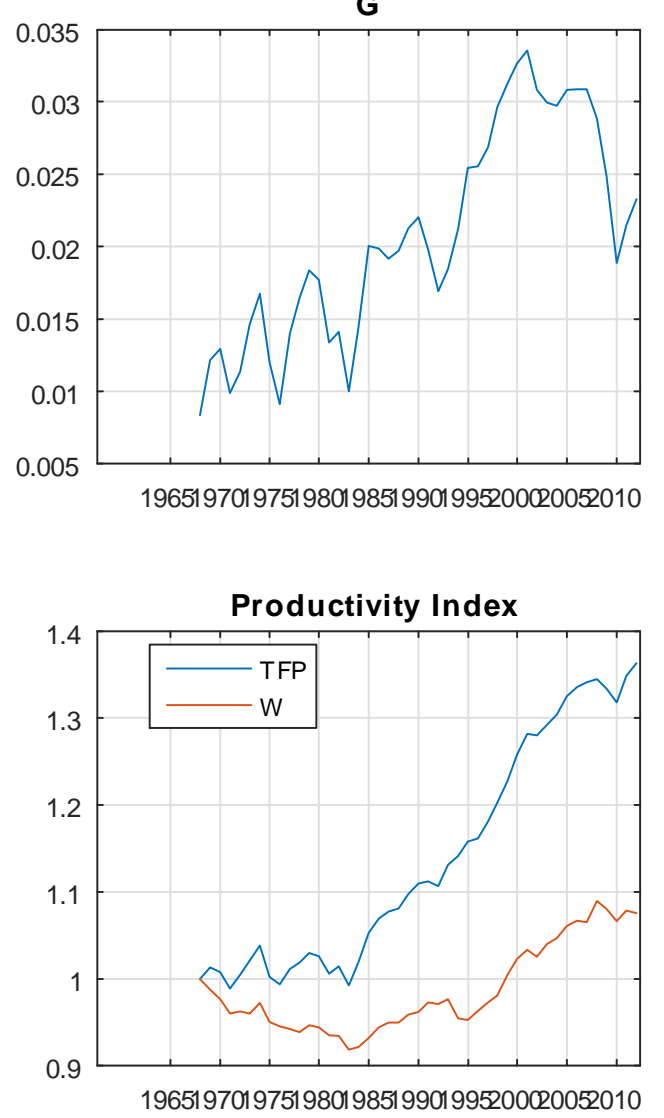

S
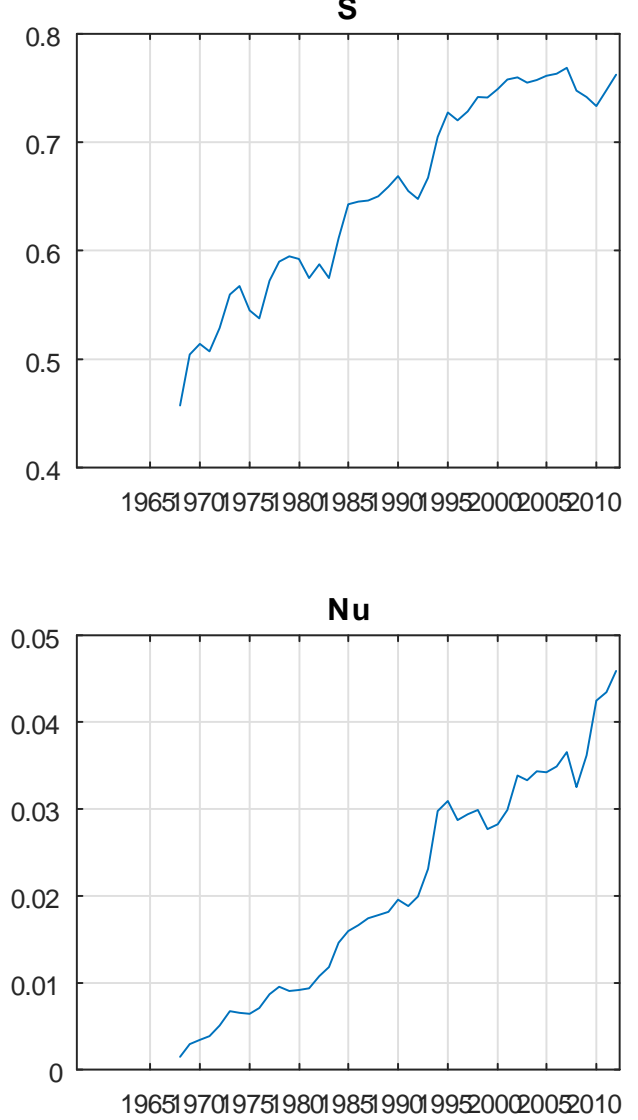

Figure 2: Estimated state variables in the US from 1967 - 2011. The first panel shows the productivity growth multiplier. The second panel show the standard deviation or dispersion of productivity. The third panel shows two productivity indexes: TFP and $w_{t}$ which is based on the productivity of the median worker. The fourth panel shows the productivity of the last person who voluntarily chooses not to work. 


\subsubsection{US Top 10\% Data}

To get a longer time period for estimation we have to substitute the income fraction of the top $10 \%$ for the ratio of mean to median household income in all three countries. Figure 3 reports the estimation in the US from $1950-2011$. The RMSE of $1.45 \%$ is higher using top $10 \%$ income data than using the ratio of mean to median income. The $r^{2}$ for the fit of actual data to the model are $88.5 \%, 90.5 \%, 78.3 \%$, and $96.9 \%$, for growth, hours per employed person, income share of the top $10 \%$, and the tax rate, respectively. The data trends are similar to 1967 - 2011, except we see that the fraction of income earned by the top $10 \%$ did not begin its upward march until the 1980s.

Figure 4 shows the estimated optimal states in the US from 1950-2011. The interesting difference between these charts and Figure 2 is in the two productivity indexes shown in Panel 3. Using top 10\% income share data over a longer time period shows that TFP and median productivity tracked each other closely until the early 1980s at which point the spread between TFP and median productivity began to widen substantially. This is about the same time that the income share of the top $10 \%$ began its steep climb.

\subsection{United Kingdom}

We estimate our model for the United Kingdom over two different time periods. During the first period from 1977 to 2011 we use annual observations on real per capita GDP growth rate, average annual hours worked per engaged person, the ratio of mean to median household income, and the ratio of total government expenditures to GDP. During the second, longer period, from 1962 to 2011, we substitute the income share of the top $10 \%$ for the ratio of mean to median household income which is not available prior to 1977.

\subsubsection{UK Mean-to-Median Ratio data}

We begin with data from the UK from 1977 to 2011. Figure 5 shows a comparison of actual data and model calculations. The fits of the model to the data are very good, but not as good as the US. The RMSE is $1.89 \%$. The $r^{2}$ are $60.0 \%, 23.3 \%, 88.6 \%$, and $89.8 \%$, for growth, hours per employed person, mean to median income, and the tax rate, respectively. We do not fit very well the downward trend in hours worked per employed person. Since 1990, mean to median income and government expenditures as a fraction of GDP have both trended upward as a result of increased dispersion in productivity as shown in Figure 6.

Figure 6 shows the optimal estimated states, $\left\{g_{t}, s_{t}, w_{t}\right\}$, and $\nu_{t}$, from 1977 - 2011. The productivity growth multiplier, shown in Panel 1, increased from 1977, approximately leveled off form 1988 - 2004 and declined afterward. The dispersion of relative productivity, shown in Panel 2, increased steadily from 1977 through 1988, but has leveled off since then. Panel 3 shows that, as in the US, both TFP and $w_{t}$ increase beginning in the early 1980s, but that TFP 

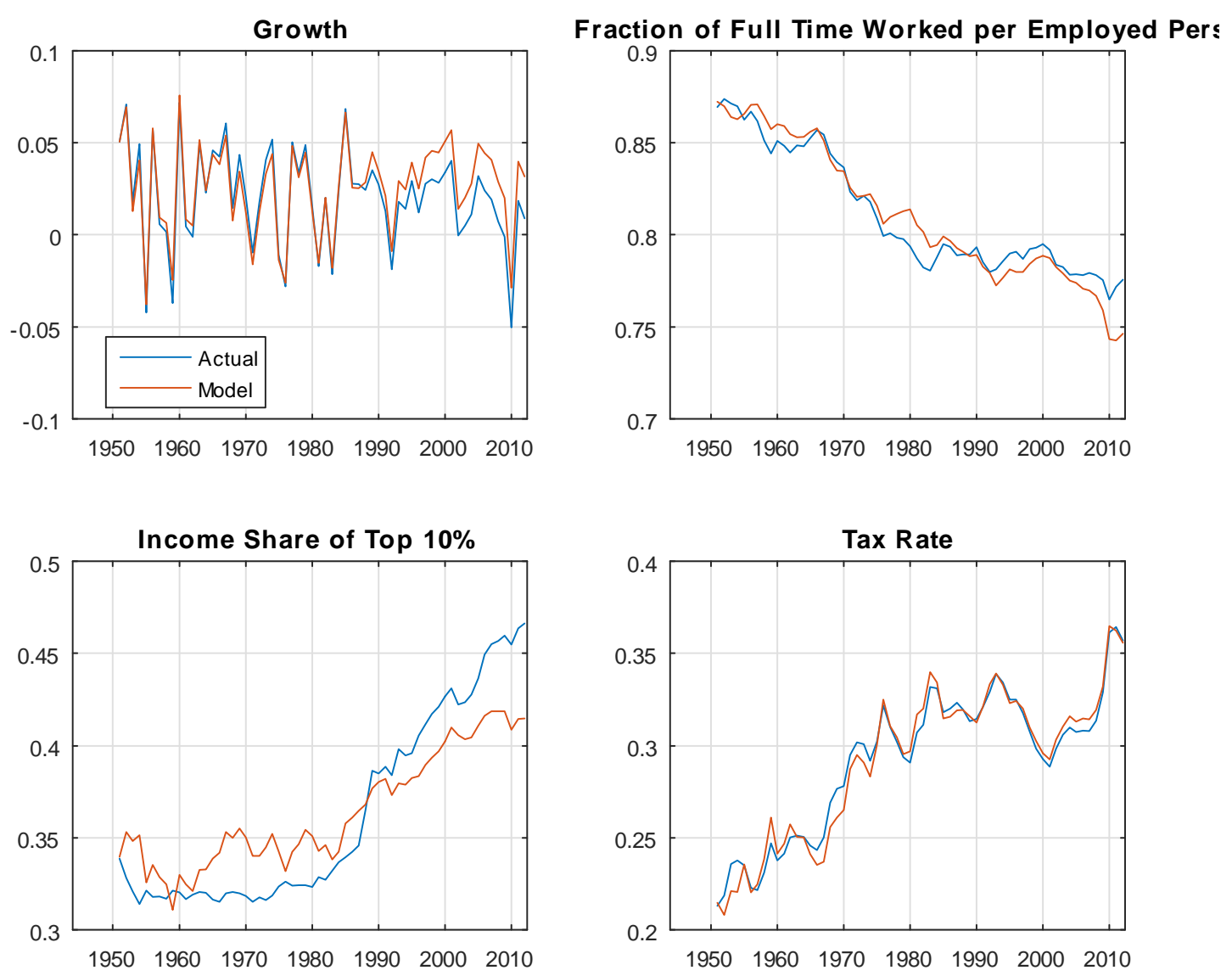

Figure 3: A comparison of actual data and model calculations for the US 1950 - 2011. Panel 1 shows a comparison of the actual rate of real per capita GDP growth to the model's calculated rate of real per capita income growth, $\gamma_{t}$. Panel 2 shows a comparison of the actual average fraction of full time hours worked per engaged person to the model's calculated average fraction of full time worked per employed person, $\bar{L}_{t}$. Panel 3 shows a comparison of the actual share of income earned by the top $10 \%$ to the model's calculated fraction of total income earned by the top $10 \%, \phi_{t}(0.1)$. Panel 4 shows a comparison of the actual ratio of total government expenditures to GDP to the model's linear tax rate, $\tau_{t}$. 

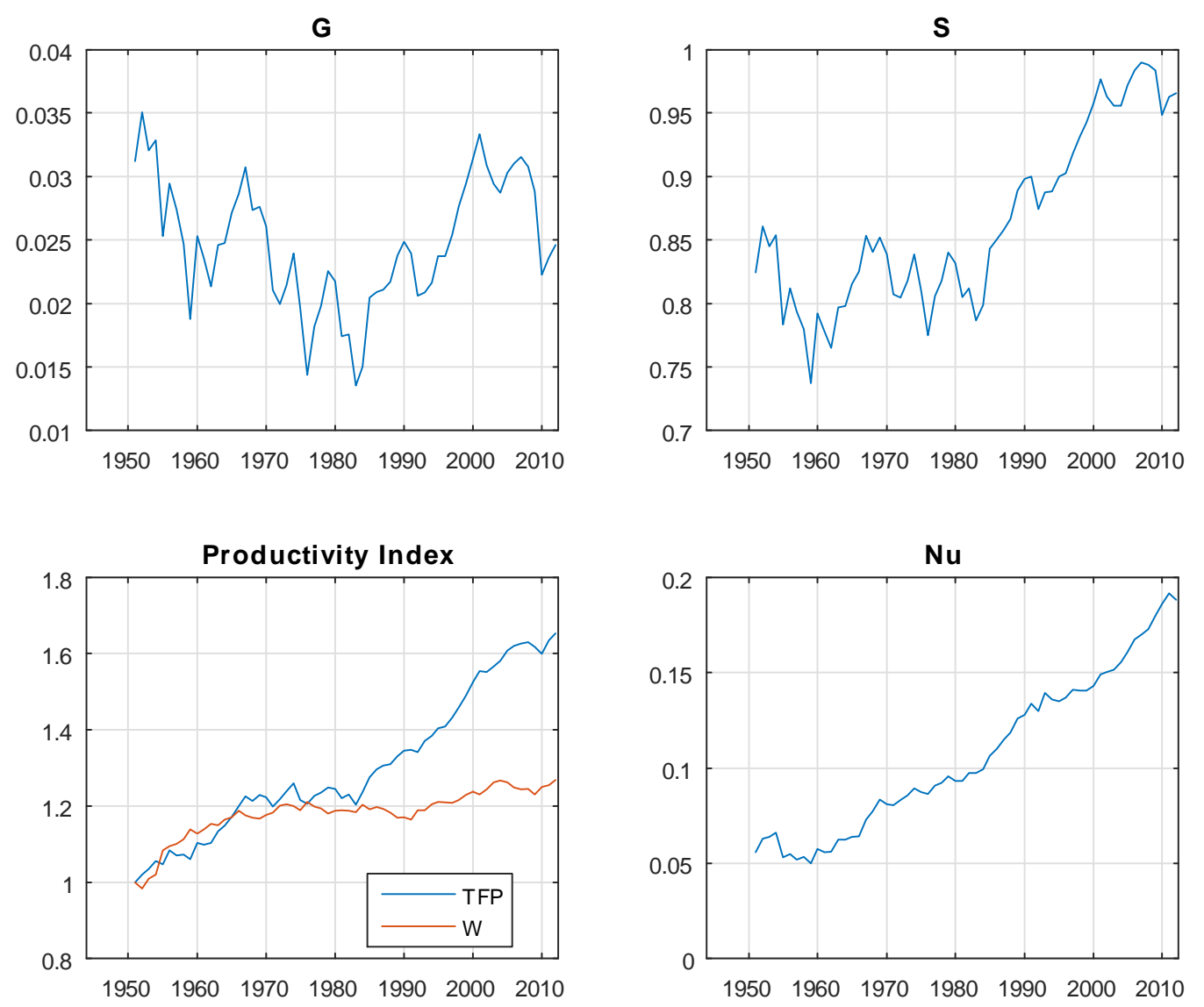

Figure 4: Estimated state variables in the US from 1950 - 2011. The first panel shows the productivity growth multiplier. The second panel show the standard deviation or dispersion of productivity. The third panel shows two productivity indexes: TFP and $w_{t}$ which is based on the productivity of the median worker. The fourth panel shows the relative productivity of the last person who voluntarily chooses not to work. 

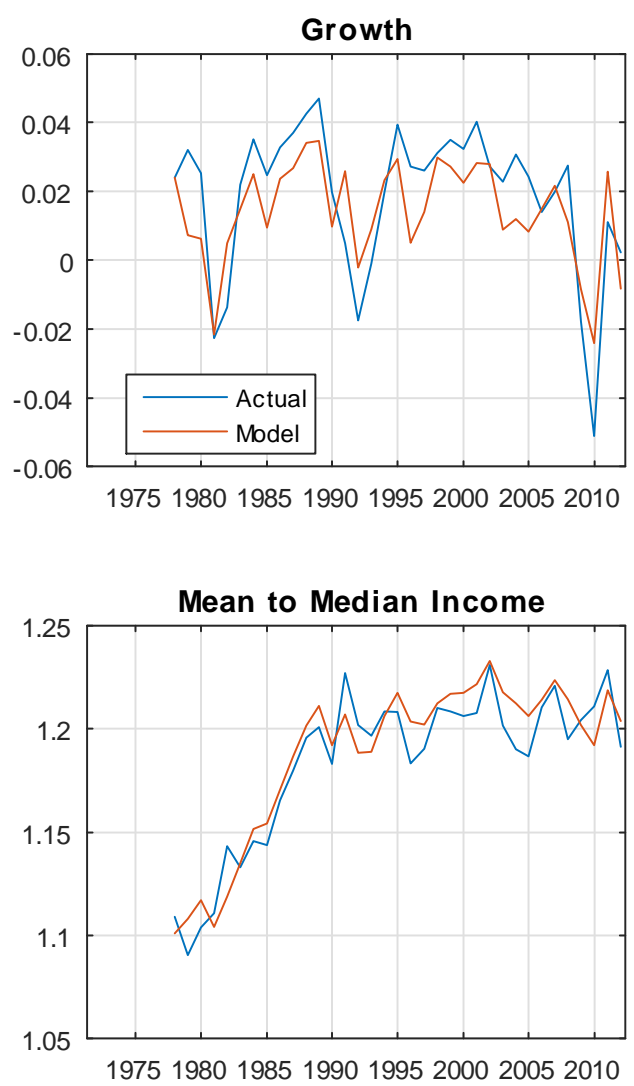
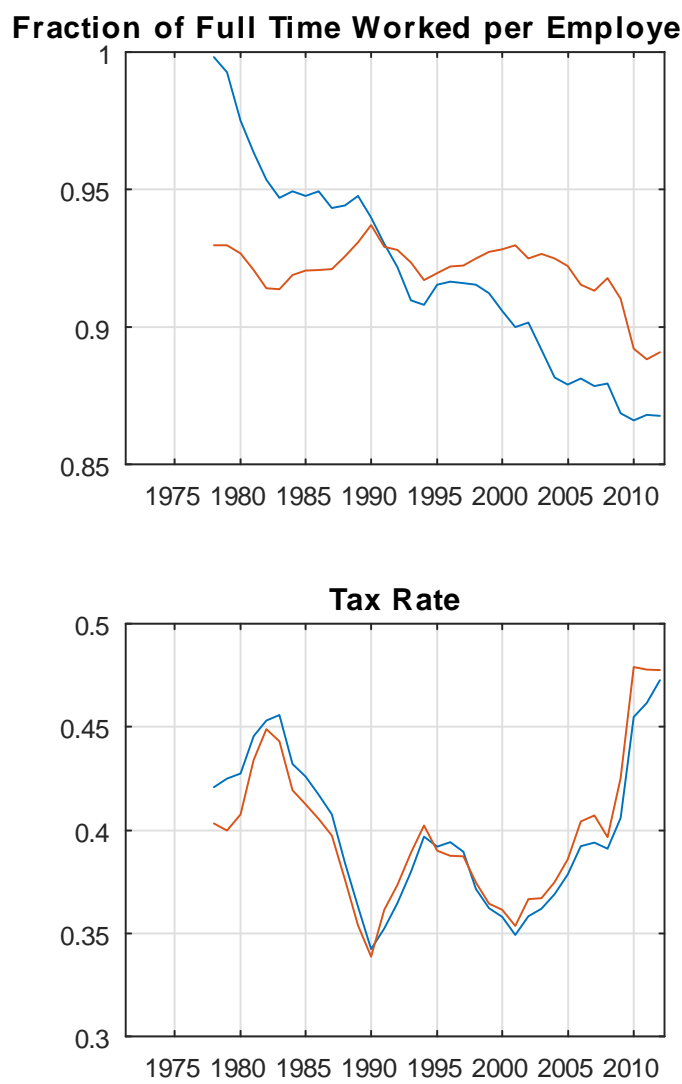

Figure 5: A comparison of actual data and model calculations for the UK 1977 - 2011. Panel 1 shows a comparison of the actual rate of real per capita GDP growth to the model's calculated rate of real per capita income growth, $\gamma_{t}$. Panel 2 shows a comparison of the actual average fraction of full time hours worked per engaged person to the model's calculated average fraction of full time worked per employed person, $\bar{L}_{t}$. Panel 3 shows the actual the ratio of mean to median income compared to the model's calculated ratio of mean to median income, $r_{t}$. Panel 4 shows a comparison of the actual ratio of total government expenditures to GDP to the model's linear tax rate, $\tau_{t}$. 
grows faster than median productivity. Panel 4 shows that in the UK, like in the US, there has been a steady upward trend in the productivity cutoff for voluntary unemployment.

\subsubsection{UK Top 10\% Data}

Figure 7 shows a comparison of actual data and model calculations. Again the RMSE of $2.54 \%$ is higher using top $10 \%$ income data than using the ratio of mean to median income. The $r^{2}$ for the fit of actual data to the model are $68.3 \%, 71.3 \%, 85.0 \%$, and $40.3 \%$, for growth, hours per employed person, income share of the top $10 \%$, and the tax rate, respectively. As in the US, the income share of the top $10 \%$ began trending upward in the 1980s, although the reported shares are lower in the UK than the US.

Figure 8 shows the estimated optimal states in the UK from 1962 - 2011. Notice in Panel 2 that, as in the US, relative productivity dispersion began to increase in the 1980s coincident with the increase of the income share of the top $10 \%$. In panel 3 we see that, using top $10 \%$ of income data, measured median productivity, $w_{t}$, has not changed much in the UK since 1962, while TFP has risen substantially.

\subsection{France}

We estimate our model for France from 1978 - 2009. We use annual observations on real per capita GDP growth rate, average annual hours worked per engaged person, the income share of the top $10 \%$, and the burden of government which is the ratio of total government expenditures to GDP. Figure 9 shows a comparison of actual data and model calculations. The RMSE of $1.55 \%$ is better than the UK (using top $10 \%$ income data), but not as good as the US. The $r^{2}$ for the fit of actual data to the model are $92.3 \%, 77.7 \%,-130.0 \%$, and $77.9 \%$, for growth, hours per employed person, income share of the top 10\%, and the tax rate, respectively. The fit of the model to the actual income share of the top $10 \%$ is poor; since 1995 the model requires a larger share for the top $10 \%$ than the

tax data shows. Of course, this discrepancy could be due to under-reporting of income on tax returns in France.

Figure 10 shows the estimated optimal states in France from 1978 - 2009. Notice in Panel 2 that, as in the US and UK, relative productivity dispersion began to increase in the 1980s coincident with the increase of the income share of the top 10\%. The biggest difference between France and the UK or US, is seen in Panel 3 which shows that TFP has been approximately stagnant in France since 1978, but that median productivity, $w_{t}$, has declined substantially. 

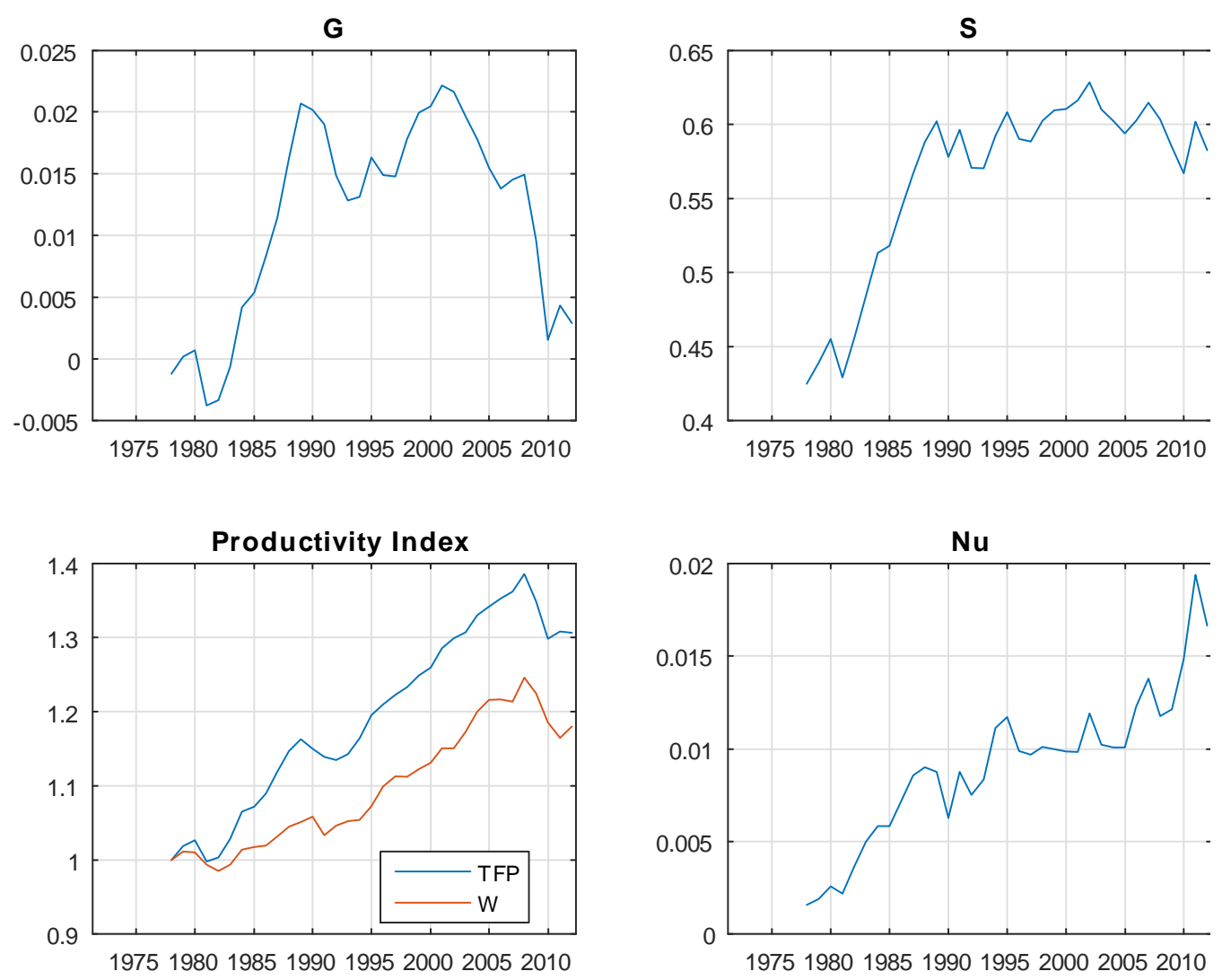

Figure 6: Estimated state variables in the UK from 1977 - 2011. The first panel shows the productivity growth multiplier. The second panel show the standard deviation or dispersion of productivity. The third panel shows two productivity indexes: TFP and $w_{t}$ which is based on the productivity of the median worker. The fourth panel shows the productivity of the last person who voluntarily chooses not to work. 

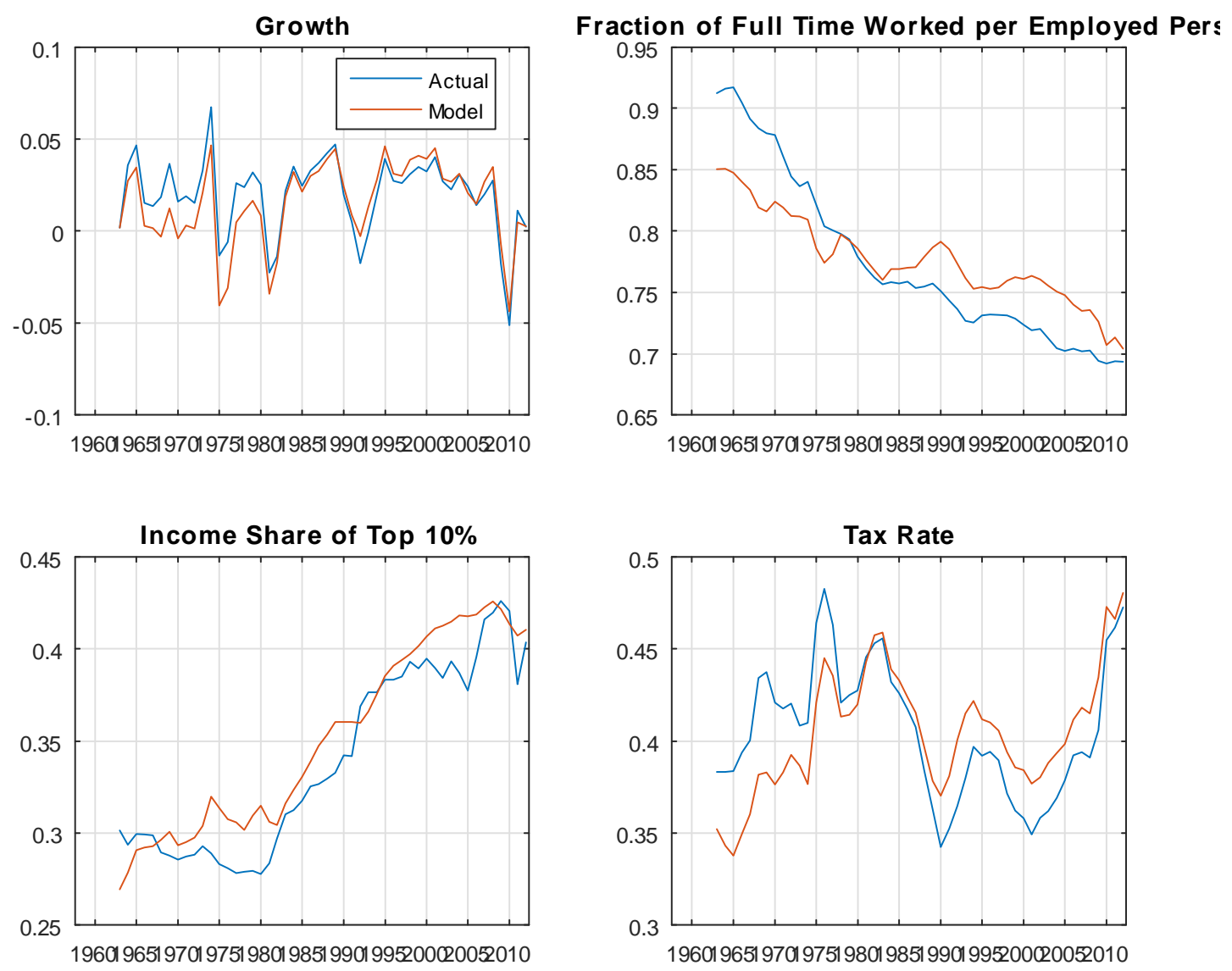

Figure 7: A comparison of actual data and model calculations for the UK 1962 - 2011. Panel 1 shows a comparison of the actual rate of real per capita GDP growth to the model's calculated rate of real per capita income growth, $\gamma_{t}$. Panel 2 shows a comparison of the actual average fraction of full time hours worked per engaged person to the model's calculated average fraction of full time worked per employed person, $\bar{L}_{t}$. Panel 3 shows a comparison of the actual share of income earned by the top $10 \%$ to the model's calculated fraction of total income earned by the top $10 \%, \phi_{t}(0.1)$. Panel 4 shows a comparison of the actual ratio of total government expenditures to GDP to the model's linear tax rate, $\tau_{t}$. 
G

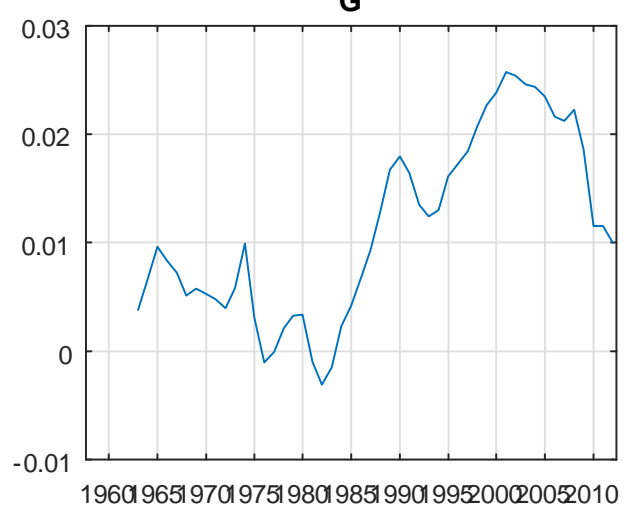

Productivity Index

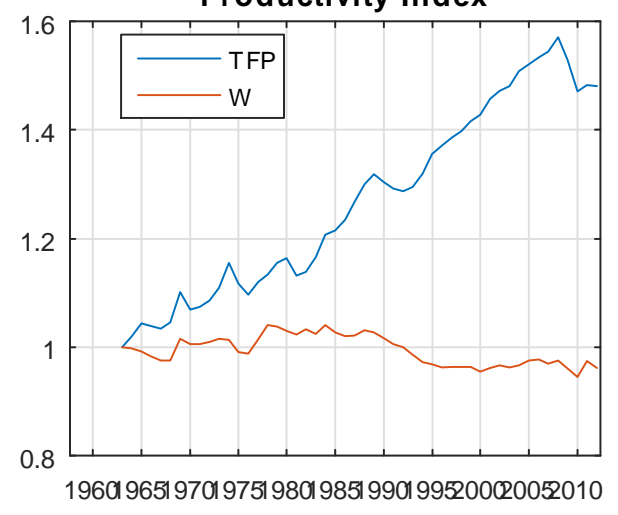

$\mathbf{S}$

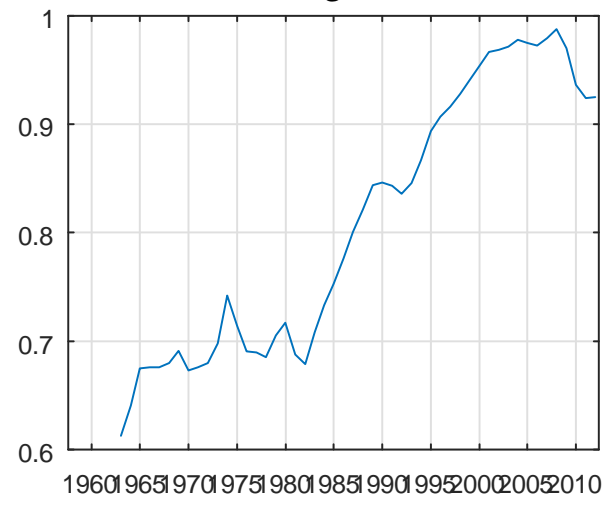

$\mathrm{Nu}$

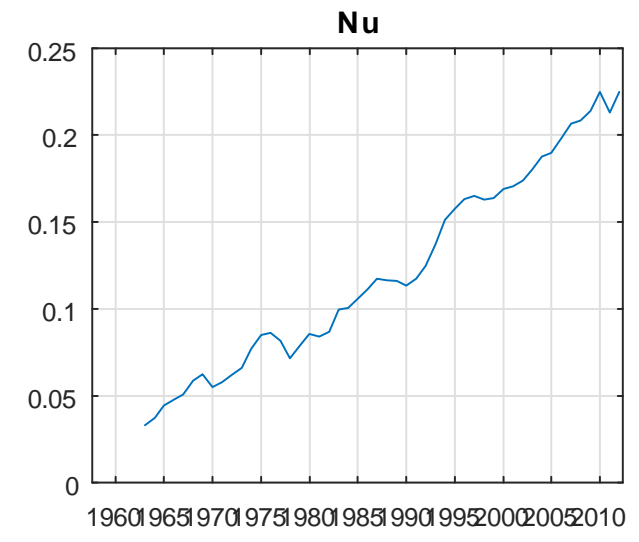

Figure 8: Estimated state variables in the UK from 1962 - 2011. The first panel shows the productivity growth multiplier. The second panel show the standard deviation or dispersion of productivity. The third panel shows two productivity indexes: TFP and $w_{t}$ which is based on the productivity of the median worker. The fourth panel shows the productivity of the last person who voluntarily chooses not to work. 

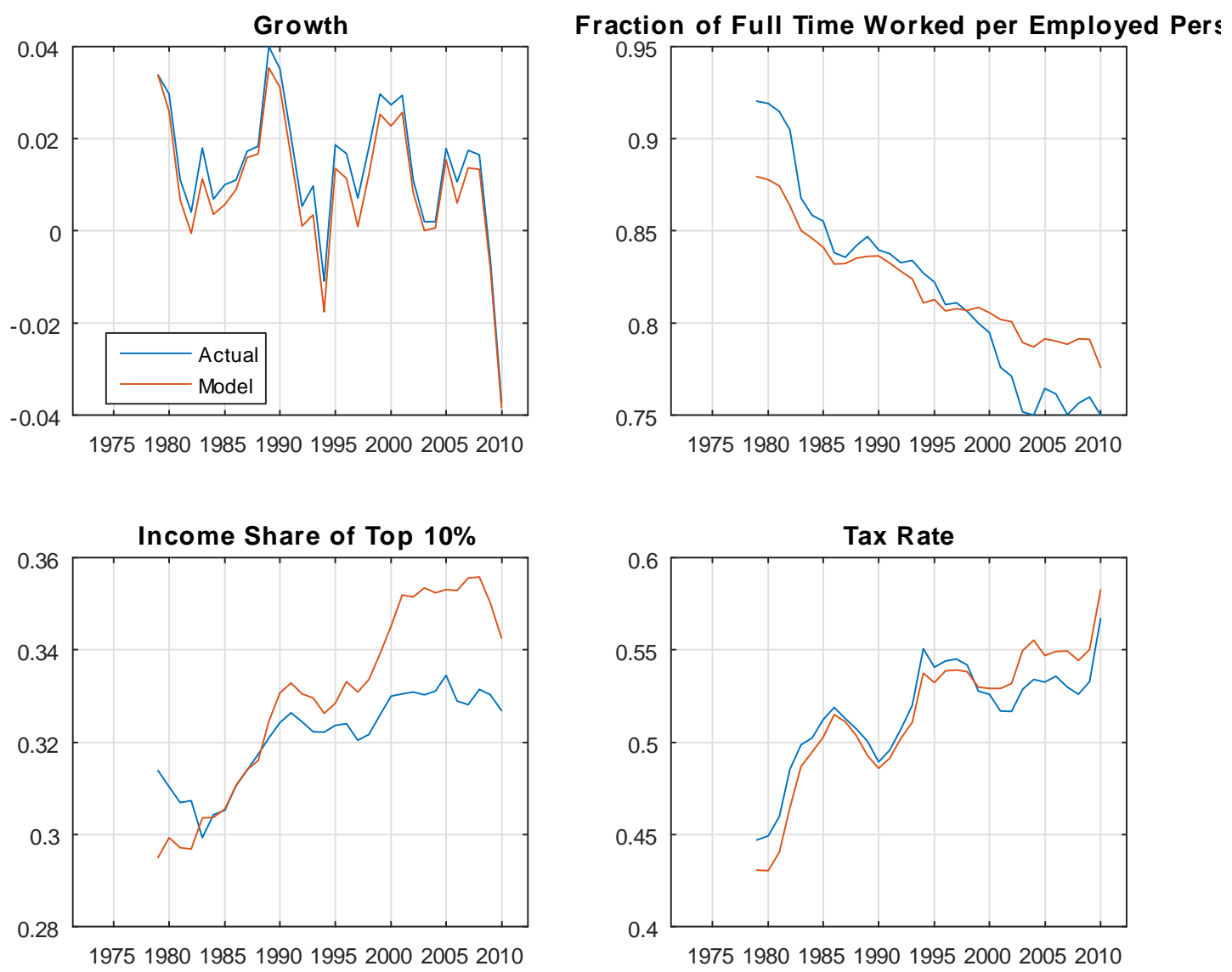

Figure 9: A comparison of actual data and model calculations for France 1978 - 2009. Panel 1 shows a comparison of the actual rate of real per capita GDP growth to the model's calculated rate of real per capita income growth, $\gamma_{t}$. Panel 2 shows a comparison of the actual average fraction of full time hours worked per engaged person to the model's calculated average fraction of full time worked per employed person, $\bar{L}_{t}$. Panel 3 shows a comparison of the actual share of income earned by the top $10 \%$ to the model's calculated fraction of total income earned by the top $10 \%, \phi_{t}(0.1)$. Panel 4 shows a comparison of the actual ratio of total government expenditures to GDP to the model's linear tax rate, $\tau_{t}$. 
G

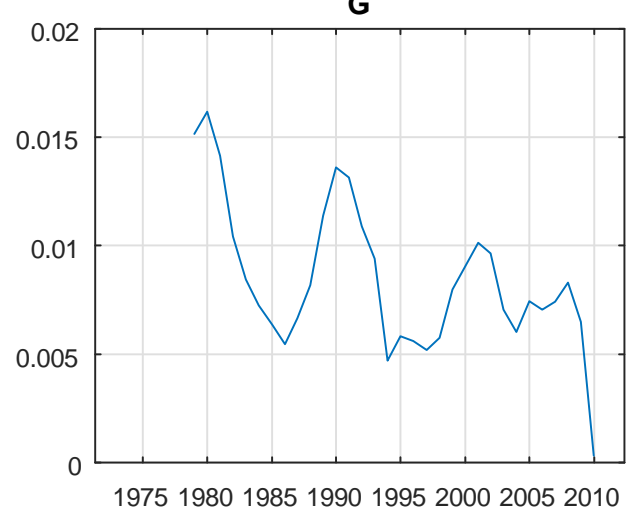

19751980198519901995200020052010

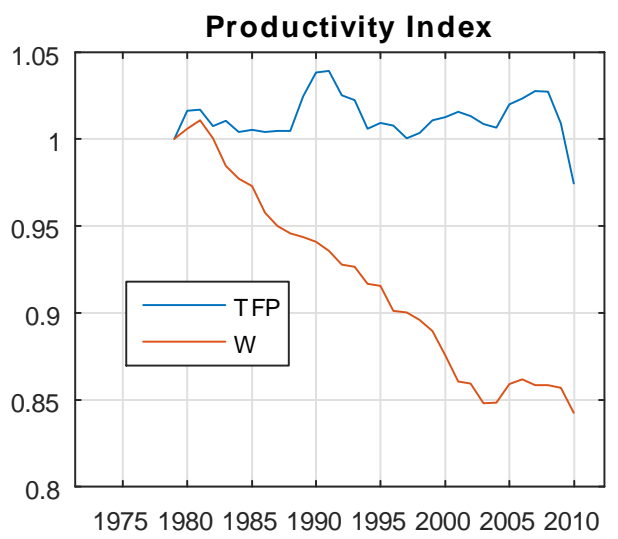

S
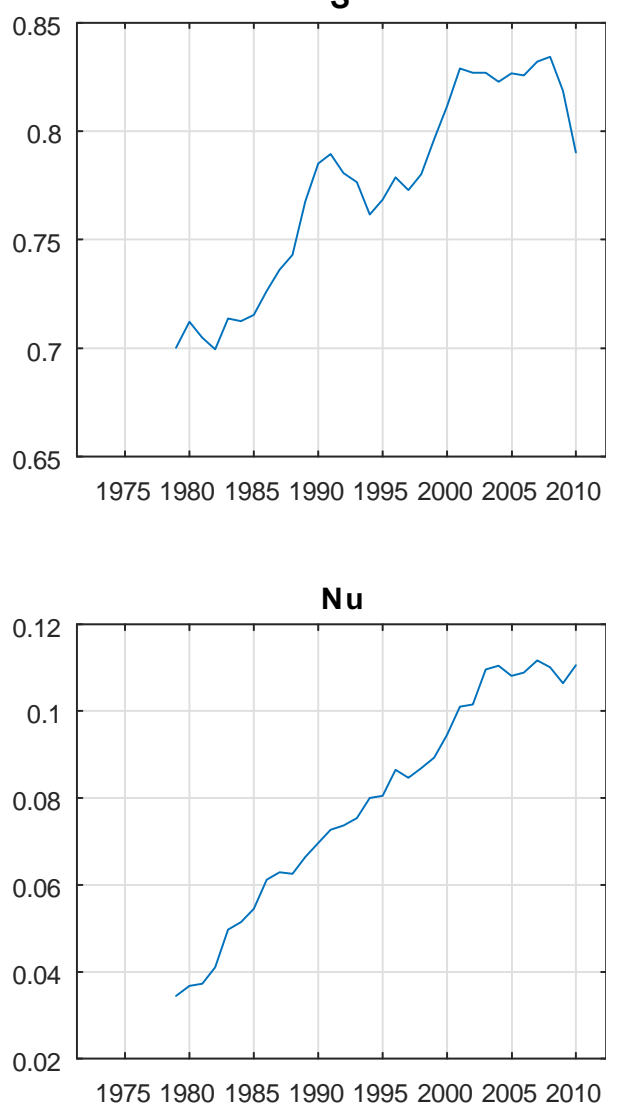

Figure 10: Estimated state variables in France from 1978 - 2009. The first panel shows the productivity growth multiplier. The second panel show the standard deviation or dispersion of productivity. The third panel shows two productivity indexes: TFP and $w_{t}$ which is based on the productivity of the median worker. The fourth panel shows the productivity of the last person who voluntarily chooses not to work. 


\subsection{Technological Specialization and the Dispersion of Pro- ductivity}

In all three countries, an important cause for the change in the distribution of productivity is technological specialization. New technologies result in divergent growth in productivity, which increase $s_{t}$. Increased returns to specialization cause the distribution of relative productivity to widen. Evidently, as shown in Panel 2 of Figures 2, 4, 6, 8, and 10, there has been a significant widening in the dispersion of relative productivity, $s_{t}$, in the U.S., UK and France, respectively. This dispersion has been attributed to the growth of computer technology. ${ }^{15}$ Those who are able to lever their skills through technology have become relatively more productive in comparison with the median worker. This technological change has increased the growth rate of the economy and the dispersion of pre-tax income.

\subsection{Statistics}

We find the standard errors of the model parameters using the outer product

of gradients estimator. The two unknown parameters in each country are the number of annual hours comprising full time work, $F$, and the maximum fraction of time devoted to work, $\alpha$.

$\begin{array}{rrr} & \alpha & \mathbf{F} \\ \text { US 1967 - 2011 } & 0.86 & 1917 \\ \text { T-stats } & (98) & (187) \\ \text { US 1950 - 2011 } & 0.74 & 2196 \\ \text { T-stats } & (40) & (91) \\ \text { UK 1962 - 2011 } & 0.79 & 2380 \\ \text { T-stats } & (19) & (29) \\ \text { UK 1977 - 2011 } & 0.91 & 1902 \\ \text { T-stats } & (56) & (73) . \\ \text { FR 1978 - 2009 } & 0.89 & 1959 \\ \text { T-stats } & (75) & (55)\end{array}$

Table 3: Estimated model parameters and their T-statstics. The estimates are asymptotically consistent.

Our estimated parameters are shown in Table 3. In the Appendix we report the state variables and their t-statistics. All of the estimated state variables are significant at the $1 \%$ level.

\footnotetext{
${ }^{15}$ See Gordon (2002). More recently Gordon and Mokyr have joined in a lively debate over whether continued technological change will fuel future productivity growth Aeppel (2014).
} 


\section{Conclusion}

Our contribution to the large and very diverse literature on growth and income distribution takes the form of a general equilibrium model of growth in labor income and consumption. The tax rate, as measured by the total government burden, and the amount spent on redistribution are endogenous variables. In developed, democratic countries voters chose the tax rate in as series of single issue elections. Since the model has no uncertainty, voters know that today's vote may be reversed at a future election. The budget is balanced, so spending and tax collections are equal. By assumption, all spending is for redistribution.

The model extends our earlier work on a static economy, Meltzer and Richard (1981), to a growing economy. Consumers are endowed with different levels of relative productivity. In our model, absolute labor productivity changes as workers learn more productive skills on the job and relative productivity changes as technology changes. ${ }^{16}$ This changes relative and absolute incomes and the spread between the top and the bottom (or other aspects) of the income distribution.

Our model analyzes consumption over time. Consumption is an endogenous variable that depends, inter alia, on taxation. Voters choose the tax rate in continuous elections. Sometimes they choose to increase current consumption by increasing tax rates and redistribution. Since higher tax rates reduce spending on learning by doing, the growth rate falls. Voters can vote to increase growth by subsequently voting to reduce tax rates to increase future consumption. The spread between top and bottom of the income distribution declines. Estimation of the model shows good correspondence to the historical data for the tax rate, average hours worked per employed person, the distribution of pre-tax income, and the growth rate of the economy which means the model captures the main facts about redistribution and economic growth.

The model answers the puzzling result emphasized by Piketty (2014). As did Karl Marx, Piketty concludes that because the return on capital repeatedly exceeds the growth rate of developed economies and does not change much over time, developed economies will face ever-increasing capital stocks. Since returns to capital go mainly to the highest income groups, the distribution of income widens over time and will continue to do so. Another possibility, of course, is that capital owners either consume or donate to charity the capital output in excess of the economic growth rate, so that capital does not accumulate faster than the economy grows. The puzzle for Piketty's conjecture is why there is no evidence anywhere that the capital stock has approached saturation. That fact opens the way for an alternative explanation of the relative constancy of the return to capital. Unlike Piketty who bases his conclusion on a comparison of the before tax income of the top 1 or 0.1 percent to before redistribution to the lowest income groups, we compare incomes available for consumption by the different income classes. Piketty's choice greatly overstates what has happened in developed countries. Our measure is more closely related to income after

\footnotetext{
${ }^{16}$ Each workers place in the distribution of relative productivity remains fixed throughout time, but the entire distribution of relative productivity can widen or narrow due to technological changes.
} 
tax and after redistribution, hence to consumption. In our model, labor is the source of income. Unlike the return to capital, the return to labor has increased considerably over time. It is subject to cyclical and other changes in relative share. And it changes with productivity growth, thereby increasing at times the relative shares of those in the working classes while reducing their relative share in periods of low growth, and therefore consumption. As Kuznets conjectured, we must look to changes in labor income to explain changes in the spread between high and low income shares. Data for the three countries we study support our model and the Kuznets' conjecture.

\section{References}

Acemoglu, Daron (2009). Introduction to Modern Economic Growth. Princeton: Princeton University Press.

Aeppel, Timothy, (2014). "Economists Debate: Has All the Important Stuff Already Been Invented?", The Wall St. Journal, June 14, 2014.

Alesina, Alberto and Rodrick, Dani, (1994). "Distributive Politics and Economic Growth," Quarterly Journal of Economics, 109, 2, May, 465-90.

Autor, David H., (2014). "Skills, education and the rise of earning inequality among the 'other 99 percent'," Science, 344, May, 844-51.

Becker, Gary S. and Tomes, Nigel, (1979). "An Equilibrium Theory of the Distribution of Income and Intergenerational Mobility," Journal of Political Economy, 87, 6, 1153-89.

Becker, Gary S. and Tomes, Nigel, (1986). "Human Capital and the Rise and Fall of Families," Journal of Labor Economics, 4, 3, Part 2, July 51-539.

Bertola, Giuseppe (1993). "Factor Shares and Saving in Endogenous Growth," American Economic Review,83,5,1184-98.

Corak, Miles, (2013). "Income Inequality, Equality of Opportunity, and Intergenerational Mobility," Journal of Economic Perspectives, 27, 3, Summer, 79-102.

Gordon, Robert J., (2002). Technology and Economic Performance in the American Economy, NBER, February, 2002.

Kaplan, Steven N. and Rauh, Joshua, (2013). "It's the Market: The BroadBased Rise in the Return to Top Talent," Journal of Economic Perspectives, 27, 3, Summer, 35-56.

Kuznets, Simon, (1955). "Economic Growth and Income Inequality," American Economic Review, 45, 1, 1-28.

Kuznets, Simon, (1979). Growth, Population and Income Distribution: Selected Essays, New York: W.W. Norton.

Meltzer, Allan H. and Richard, Scott, F., (1981). "A Rational Theory of the Size of Government," Journal of Political Economy, 89, 5, 914-27. 
Okun, Arthur, (1975). Equality and Efficiency: The Big Tradeoff, Washington: Brookings.

Perri, Fabrizio, (2014). "Inequality," Annual Report, Federal Reserve Bank of Minneapolis, 5-27.

Persson, Torsten and Tabellini, Guido (1994). "Is Inequality Harmful for Growth?," American Economic Review, 84,3, 600-621.

Piguillem, Facundo and Anderson L. Schneider (2013). "Heterogeneous Labor skills, the Median voter and Labor Taxes," Review of Economics Dynamics, 16, April 2013, 332-349.

Piketty, Thomas, (2014). Capital in the Twenty-First Century, translated by Arthur Goldhammner, Cambridge, MA., Belknap Press.

Roberts, Kevin W. S., (1977). "Voting Over Income Tax Schedules," Journal of Public Economics, 8, 329-40.

Roberts, Kevin,(2015), "Dynamic voting in clubs", Research in Economics, this Volume.

Romer, Thomas, (1975). "Individual welfare, majority voting, and the properties of a linear income tax," Journal of Public Economics, 4, February 1975, 163-185.

Roine, Joseph and Waldenstrom, Daniel, (2006). "The Evolution of Incomes in an Egalitarian Society: Sweden 1903-2004," Stockholm School of Economics.

Rosen, Sherwin, (1981). "The Economics of Superstars," American Economic Review, 71, 5, 845-58.

Saez, Emanuel, (2013). "Income Inequality: Evidence and Policy Implications," Arrow Lecture, Stanford University, January.

\section{A Data Appendix}

In this Appendix we report the state estimates and their T-statistics. We find the standard errors of the model parameters using the outer product of gradients estimator. Because we calculate $g_{t}$ from equation (61) as a function of $\ln \left(\nu_{t}\right)$ we report $\ln \left(\nu_{t}\right)$ as the first state variable instead of $g_{t}$ and $s_{t}$ as the second state variable. The estimates for the US in 1967-2011 using the ratio of mean to median household income as a measure of income dispersion are reported in Table 4. Because of the sensitivity of the log-likelihood to state changes, all of the estimated states are significant at the $1 \%$ level. Next, in Tables 5 and its continuation in 6, we report the state estimates for the US from 1950-2011 using the income share of the top $10 \%$ as a measure of income dispersion. Again all estimates are significant at the $1 \%$ level. Finally, we report the state estimates and T-statistics for the UK from 1977-2011, the UK from 1962-2011, and France from 1978-2009 in Tables 6, 8, and 9, respectively. Once again, all estimates are significant at the $1 \%$ level. 


$\begin{array}{lrrrr} & \ln (\nu) & \text { T-Statistic } & \text { S } & \text { T-Statistic } \\ \text { Dec-67 } & -6.50 & -15.17 & 0.46 & 18.39 \\ \text { Dec-68 } & -5.82 & -25.35 & 0.50 & 36.42 \\ \text { Dec-69 } & -5.68 & -25.31 & 0.51 & 40.86 \\ \text { Dec-70 } & -5.55 & -13.47 & 0.51 & 19.43 \\ \text { Dec-71 } & -5.27 & -22.76 & 0.53 & 41.74 \\ \text { Dec-72 } & -4.99 & -32.57 & 0.56 & 74.61 \\ \text { Dec-73 } & -5.02 & -37.88 & 0.57 & 111.08 \\ \text { Dec-74 } & -5.04 & -3.19 & 0.54 & 6.70 \\ \text { Dec-75 } & -4.94 & -6.74 & 0.54 & 15.45 \\ \text { Dec-76 } & -4.74 & -20.07 & 0.57 & 56.19 \\ \text { Dec-77 } & -4.64 & -23.47 & 0.59 & 75.59 \\ \text { Dec-78 } & -4.70 & -35.23 & 0.59 & 121.31 \\ \text { Dec-79 } & -4.69 & -26.15 & 0.59 & 76.37 \\ \text { Dec-80 } & -4.66 & -16.55 & 0.57 & 19.26 \\ \text { Dec-81 } & -4.53 & -25.70 & 0.59 & 39.30 \\ \text { Dec-82 } & -4.44 & -28.11 & 0.57 & 46.08 \\ \text { Dec-83 } & -4.22 & -11.81 & 0.61 & 36.92 \\ \text { Dec-84 } & -4.13 & -32.77 & 0.64 & 107.16 \\ \text { Dec-85 } & -4.09 & -31.50 & 0.65 & 104.66 \\ \text { Dec-86 } & -4.05 & -26.78 & 0.65 & 86.49 \\ \text { Dec-87 } & -4.02 & -19.30 & 0.65 & 61.98 \\ \text { Dec-88 } & -4.01 & -21.24 & 0.66 & 68.84 \\ \text { Dec-89 } & -3.93 & -13.90 & 0.67 & 43.70 \\ \text { Dec-90 } & -3.97 & -19.15 & 0.66 & 56.41 \\ \text { Dec-91 } & -3.91 & -21.61 & 0.65 & 37.87 \\ \text { Dec-92 } & -3.76 & -8.62 & 0.67 & 30.97 \\ \text { Dec-93 } & -3.51 & -32.70 & 0.70 & 107.85 \\ \text { Dec-94 } & -3.47 & -20.38 & 0.73 & 63.11 \\ \text { Dec-95 } & -3.55 & -13.89 & 0.72 & 22.43 \\ \text { Dec-96 } & -3.52 & -4.74 & 0.73 & 10.96 \\ \text { Dec-97 } & -3.51 & -9.41 & 0.74 & 20.78 \\ \text { Dec-98 } & -3.58 & -16.36 & 0.74 & 40.65 \\ \text { Dec-99 } & -3.56 & -9.98 & 0.75 & 26.38 \\ \text { Dec-00 } & -3.51 & -9.56 & 0.76 & 40.00 \\ \text { Dec-01 } & -3.38 & -34.91 & 0.76 & 115.02 \\ \text { Dec-02 } & -3.40 & -23.59 & 0.75 & 69.91 \\ \text { Dec-03 } & -3.37 & -18.22 & 0.76 & 38.76 \\ \text { Dec-04 } & -3.37 & -8.84 & 0.76 & 11.07 \\ \text { Dec-05 } & -3.35 & -14.94 & 0.76 & 30.69 \\ \text { Dec-06 } & -3.31 & -25.47 & 0.77 & 59.75 \\ \text { Dec-07 } & -3.42 & -13.65 & 0.75 & 44.71 \\ \text { Dec-08 } & -3.32 & -32.59 & 0.74 & 109.62 \\ \text { Dec-09 } & -3.15 & -39.05 & 0.73 & 167.76 \\ \text { Dec-10 } & -3.13 & -28.46 & 0.75 & 100.24 \\ \text { Dec-11 } & -3.08 & -40.90 & 0.76 & 154.59 \\ & & & & \end{array}$

Table 4: Estimated states and t-statistics for the US 1967-2011. 


$\begin{array}{lrrrr} & \ln (\nu) & \text { T-Statistic } & \mathrm{S} & \text { T-Statistic } \\ \text { Dec-50 } & -2.88 & -3.75 & 0.82 & 6.05 \\ \text { Dec-51 } & -2.77 & -18.54 & 0.86 & 43.82 \\ \text { Dec-52 } & -2.75 & -22.91 & 0.84 & 53.59 \\ \text { Dec-53 } & -2.72 & -26.06 & 0.85 & 67.66 \\ \text { Dec-54 } & -2.94 & -4.52 & 0.78 & 13.32 \\ \text { Dec-55 } & -2.90 & -8.81 & 0.81 & 27.20 \\ \text { Dec-56 } & -2.96 & -11.84 & 0.79 & 22.70 \\ \text { Dec-57 } & -2.93 & -14.94 & 0.78 & 23.99 \\ \text { Dec-58 } & -3.00 & -16.09 & 0.74 & 23.70 \\ \text { Dec-59 } & -2.85 & -12.01 & 0.79 & 21.70 \\ \text { Dec-60 } & -2.89 & -12.57 & 0.78 & 18.49 \\ \text { Dec-61 } & -2.88 & -10.72 & 0.77 & 15.45 \\ \text { Dec-62 } & -2.78 & -7.46 & 0.80 & 18.31 \\ \text { Dec-63 } & -2.77 & -8.22 & 0.80 & 19.98 \\ \text { Dec-64 } & -2.75 & -12.14 & 0.82 & 36.16 \\ \text { Dec-65 } & -2.75 & -16.41 & 0.83 & 47.43 \\ \text { Dec-66 } & -2.62 & -22.60 & 0.85 & 61.33 \\ \text { Dec-67 } & -2.56 & -21.97 & 0.84 & 58.20 \\ \text { Dec-68 } & -2.49 & -24.73 & 0.85 & 67.84 \\ \text { Dec-69 } & -2.52 & -22.23 & 0.84 & 60.28 \\ \text { Dec-70 } & -2.52 & -16.89 & 0.81 & 45.71 \\ \text { Dec-71 } & -2.49 & -15.14 & 0.80 & 42.93 \\ \text { Dec-72 } & -2.46 & -19.68 & 0.82 & 52.83 \\ \text { Dec-73 } & -2.42 & -19.78 & 0.84 & 59.47 \\ \text { Dec-74 } & -2.44 & -12.76 & 0.81 & 29.83 \\ \text { Dec-75 } & -2.45 & -8.86 & 0.78 & 12.68 \\ \text { Dec-76 } & -2.40 & -14.22 & 0.81 & 27.41 \\ \text { Dec-77 } & -2.39 & -19.09 & 0.82 & 36.03 \\ \text { Dec-78 } & -2.35 & -22.13 & 0.84 & 47.58 \\ \text { Dec-79 } & -2.37 & -25.30 & 0.83 & 43.07 \\ \text { Dec-80 } & -2.37 & -18.89 & 0.81 & 23.81 \\ \text { Dec-81 } & -2.33 & -22.21 & 0.81 & 30.07 \\ \text { Dec-82 } & -2.33 & -12.83 & 0.79 & 16.69 \\ \text { Dec-83 } & -2.31 & -8.81 & 0.80 & 13.67 \\ \text { Dec-84 } & -2.24 & -11.23 & 0.84 & 29.63 \\ \text { Dec-85 } & -2.21 & -11.99 & 0.85 & 31.08 \\ \text { Dec-86 } & -2.16 & -12.10 & 0.86 & 32.18 \\ \text { Dec-87 } & -2.13 & -2.70 & 0.87 & 11.75 \\ \text { Dec-88 } & -2.07 & -6.80 & 0.89 & 25.48 \\ \text { Dec-89 } & -2.06 & -6.62 & 0.90 & 22.58 \\ \text { Dec-90 } & -2.01 & -4.89 & 0.90 & 21.50 \\ & & & & \end{array}$

Table 5: Estimated states and t-statistics for the US 1950-2011, part 1 


$\begin{array}{lrrrr} & \ln (\nu) & \text { T-Statistic } & \mathrm{S} & \text { T-Statistic } \\ \text { Dec-91 } & -2.04 & -8.73 & 0.87 & 30.61 \\ \text { Dec-92 } & -1.97 & -14.51 & 0.89 & 46.26 \\ \text { Dec-93 } & -2.00 & -14.13 & 0.89 & 44.69 \\ \text { Dec-94 } & -2.00 & -13.13 & 0.90 & 44.16 \\ \text { Dec-95 } & -1.99 & -17.19 & 0.90 & 56.19 \\ \text { Dec-96 } & -1.96 & -14.84 & 0.92 & 59.93 \\ \text { Dec-97 } & -1.96 & -15.79 & 0.93 & 65.29 \\ \text { Dec-98 } & -1.96 & -15.41 & 0.94 & 67.86 \\ \text { Dec-99 } & -1.94 & -15.34 & 0.96 & 71.12 \\ \text { Dec-00 } & -1.90 & -13.49 & 0.98 & 67.62 \\ \text { Dec-01 } & -1.90 & -11.98 & 0.96 & 55.97 \\ \text { Dec-02 } & -1.89 & -13.49 & 0.96 & 62.29 \\ \text { Dec-03 } & -1.86 & -15.60 & 0.96 & 69.68 \\ \text { Dec-04 } & -1.83 & -16.46 & 0.97 & 77.81 \\ \text { Dec-05 } & -1.79 & -20.21 & 0.98 & 94.65 \\ \text { Dec-06 } & -1.77 & -21.73 & 0.99 & 103.33 \\ \text { Dec-07 } & -1.75 & -22.95 & 0.99 & 108.31 \\ \text { Dec-08 } & -1.71 & -25.25 & 0.98 & 114.23 \\ \text { Dec-09 } & -1.68 & -28.85 & 0.95 & 114.80 \\ \text { Dec-10 } & -1.65 & -30.53 & 0.96 & 121.55 \\ \text { Dec-11 } & -1.67 & -31.05 & 0.97 & 122.31\end{array}$

Table 6: Estimated states and t-statistics for the US 1950-2011, part 2 


$\begin{array}{lrrrr} & \ln (\nu) & \text { T-Statistic } & \mathrm{S} & \text { T-Statistic } \\ \text { Dec-77 } & -6.47 & -8.19 & 0.42 & 9.95 \\ \text { Dec-78 } & -6.27 & -10.09 & 0.44 & 14.50 \\ \text { Dec-79 } & -5.96 & -9.46 & 0.46 & 14.04 \\ \text { Dec-80 } & -6.12 & -7.77 & 0.43 & 8.83 \\ \text { Dec-81 } & -5.61 & -11.95 & 0.46 & 18.15 \\ \text { Dec-82 } & -5.30 & -7.12 & 0.48 & 8.12 \\ \text { Dec-83 } & -5.15 & -8.76 & 0.51 & 11.07 \\ \text { Dec-84 } & -5.15 & -9.81 & 0.52 & 13.92 \\ \text { Dec-85 } & -4.93 & -8.74 & 0.54 & 11.71 \\ \text { Dec-86 } & -4.76 & -9.02 & 0.57 & 13.16 \\ \text { Dec-87 } & -4.71 & -8.73 & 0.59 & 13.65 \\ \text { Dec-88 } & -4.74 & -10.00 & 0.60 & 18.16 \\ \text { Dec-89 } & -5.07 & -6.01 & 0.58 & 15.72 \\ \text { Dec-90 } & -4.74 & -11.71 & 0.60 & 30.67 \\ \text { Dec-91 } & -4.89 & -9.73 & 0.57 & 20.57 \\ \text { Dec-92 } & -4.79 & -8.35 & 0.57 & 13.73 \\ \text { Dec-93 } & -4.50 & -5.66 & 0.59 & 8.29 \\ \text { Dec-94 } & -4.45 & -5.18 & 0.61 & 16.28 \\ \text { Dec-95 } & -4.62 & -10.54 & 0.59 & 27.66 \\ \text { Dec-96 } & -4.64 & -6.35 & 0.59 & 17.53 \\ \text { Dec-97 } & -4.60 & -4.65 & 0.60 & 6.82 \\ \text { Dec-98 } & -4.61 & -7.39 & 0.61 & 14.63 \\ \text { Dec-99 } & -4.62 & -9.66 & 0.61 & 20.06 \\ \text { Dec-00 } & -4.62 & -11.20 & 0.62 & 23.42 \\ \text { Dec-01 } & -4.43 & -9.30 & 0.63 & 11.94 \\ \text { Dec-02 } & -4.58 & -12.90 & 0.61 & 25.92 \\ \text { Dec-03 } & -4.60 & -14.21 & 0.60 & 35.07 \\ \text { Dec-04 } & -4.60 & -13.75 & 0.59 & 30.28 \\ \text { Dec-05 } & -4.40 & -6.29 & 0.60 & 6.65 \\ \text { Dec-06 } & -4.28 & -11.33 & 0.61 & 13.59 \\ \text { Dec-07 } & -4.44 & -14.29 & 0.60 & 26.60 \\ \text { Dec-08 } & -4.41 & -14.14 & 0.58 & 18.18 \\ \text { Dec-09 } & -4.21 & -13.86 & 0.57 & 25.86 \\ \text { Dec-10 } & -3.94 & -11.73 & 0.60 & 21.48 \\ \text { Dec-11 } & -4.09 & -11.58 & 0.58 & 18.69 \\ & & & & \end{array}$

Table 7: Estimated states and t-statistics for the UK 1977-2011 


\begin{tabular}{|c|c|c|c|c|}
\hline & $\ln (\nu)$ & T-Statistic & $\mathrm{S}$ & T-Statistic \\
\hline Dec-62 & -3.40 & -7.76 & 0.61 & 12.89 \\
\hline Dec-63 & -3.28 & -6.75 & 0.64 & 11.69 \\
\hline Dec-64 & -3.11 & -6.85 & 0.68 & 12.65 \\
\hline Dec-65 & -3.04 & -7.04 & 0.68 & 12.76 \\
\hline Dec-66 & -2.98 & -7.69 & 0.68 & 13.86 \\
\hline Dec-67 & -2.84 & -8.13 & 0.68 & 15.76 \\
\hline Dec-68 & -2.77 & -8.39 & 0.69 & 17.07 \\
\hline Dec-69 & -2.90 & -8.10 & 0.67 & 15.04 \\
\hline Dec-70 & -2.85 & -7.97 & 0.68 & 13.66 \\
\hline Dec-71 & -2.78 & -7.91 & 0.68 & 12.82 \\
\hline Dec-72 & -2.72 & -8.61 & 0.70 & 14.43 \\
\hline Dec-73 & -2.57 & -10.70 & 0.74 & 20.70 \\
\hline Dec-74 & -2.47 & -10.54 & 0.71 & 21.69 \\
\hline Dec-75 & -2.45 & -9.77 & 0.69 & 19.71 \\
\hline Dec-76 & -2.50 & -9.00 & 0.69 & 17.76 \\
\hline Dec-77 & -2.64 & -5.10 & 0.69 & 12.74 \\
\hline Dec-78 & -2.54 & -6.58 & 0.71 & 15.94 \\
\hline Dec-79 & -2.46 & -7.03 & 0.72 & 18.57 \\
\hline Dec-80 & -2.48 & -4.77 & 0.69 & 11.55 \\
\hline Dec-81 & -2.44 & -2.86 & 0.68 & 4.50 \\
\hline Dec-82 & -2.31 & -2.11 & 0.71 & 3.97 \\
\hline Dec-83 & -2.30 & -4.42 & 0.73 & 6.16 \\
\hline Dec-84 & -2.25 & -4.94 & 0.75 & 7.07 \\
\hline Dec-85 & -2.20 & -5.17 & 0.78 & 8.14 \\
\hline Dec-86 & -2.14 & -7.07 & 0.80 & 11.37 \\
\hline Dec-87 & -2.15 & -8.40 & 0.82 & 12.89 \\
\hline Dec-88 & -2.15 & -9.32 & 0.84 & 15.15 \\
\hline Dec-89 & -2.18 & -9.11 & 0.85 & 13.46 \\
\hline Dec-90 & -2.14 & -10.32 & 0.84 & 14.55 \\
\hline Dec-91 & -2.08 & -9.54 & 0.84 & 14.78 \\
\hline Dec-92 & -1.99 & -8.99 & 0.85 & 14.80 \\
\hline Dec-93 & -1.89 & -7.16 & 0.87 & 11.30 \\
\hline Dec-94 & -1.85 & -6.19 & 0.89 & 9.72 \\
\hline Dec-95 & -1.81 & -5.81 & 0.91 & 8.88 \\
\hline Dec-96 & -1.80 & -6.49 & 0.92 & 10.11 \\
\hline Dec-97 & -1.81 & -7.06 & 0.93 & 11.22 \\
\hline Dec-98 & -1.81 & -8.17 & 0.94 & 13.45 \\
\hline Dec-99 & -1.78 & -8.33 & 0.95 & 14.35 \\
\hline Dec-00 & -1.77 & -9.21 & 0.97 & 16.47 \\
\hline Dec-01 & -1.75 & -9.74 & 0.97 & 18.19 \\
\hline Dec-02 & -1.71 & -9.01 & 0.97 & 15.99 \\
\hline Dec-03 & -1.67 & -10.17 & 0.98 & 19.86 \\
\hline Dec-04 & -1.66 & -10.68 & 0.97 & 23.64 \\
\hline Dec-05 & -1.62 & -9.08 & 0.97 & 15.78 \\
\hline Dec-06 & -1.58 & -7.64 & 0.98 & 13.40 \\
\hline Dec-07 & -1.57 & -7.58 & 0.99 & 13.39 \\
\hline Dec-08 & -1.54 & -7.20 & 0.97 & 13.33 \\
\hline Dec-09 & -1.49 & 45.47 & 0.94 & 11.50 \\
\hline Dec-10 & -1.55 & -7.33 & 0.92 & 16.03 \\
\hline Dec-11 & -1.49 & -2.93 & 0.93 & 4.43 \\
\hline
\end{tabular}

Table 8: Estimated states and t-statistics for the UK 1962-2011. 


$\begin{array}{lrrrr} & \ln (\nu) & \text { T-Statistic } & \mathrm{S} & \text { T-Statistic } \\ \text { Dec-78 } & -3.37 & -13.45 & 0.70 & 23.48 \\ \text { Dec-79 } & -3.30 & -11.79 & 0.71 & 20.02 \\ \text { Dec-80 } & -3.29 & -11.64 & 0.70 & 19.50 \\ \text { Dec-81 } & -3.19 & -12.44 & 0.70 & 20.63 \\ \text { Dec-82 } & -3.00 & -10.81 & 0.71 & 16.77 \\ \text { Dec-83 } & -2.97 & -8.41 & 0.71 & 11.04 \\ \text { Dec-84 } & -2.91 & -8.45 & 0.72 & 10.84 \\ \text { Dec-85 } & -2.79 & -5.33 & 0.73 & 6.59 \\ \text { Dec-86 } & -2.77 & -4.07 & 0.74 & 5.16 \\ \text { Dec-87 } & -2.77 & -6.81 & 0.74 & 8.63 \\ \text { Dec-88 } & -2.71 & -9.09 & 0.77 & 11.81 \\ \text { Dec-89 } & -2.66 & -7.97 & 0.79 & 13.71 \\ \text { Dec-90 } & -2.62 & -9.10 & 0.79 & 14.91 \\ \text { Dec-91 } & -2.61 & -9.14 & 0.78 & 15.55 \\ \text { Dec-92 } & -2.58 & -11.79 & 0.78 & 18.07 \\ \text { Dec-93 } & -2.52 & -12.42 & 0.76 & 17.94 \\ \text { Dec-94 } & -2.52 & -10.87 & 0.77 & 16.54 \\ \text { Dec-95 } & -2.45 & -9.63 & 0.78 & 18.43 \\ \text { Dec-96 } & -2.47 & -10.34 & 0.77 & 19.77 \\ \text { Dec-97 } & -2.44 & -8.93 & 0.78 & 20.46 \\ \text { Dec-98 } & -2.42 & -9.11 & 0.80 & 22.25 \\ \text { Dec-99 } & -2.36 & -11.25 & 0.81 & 24.69 \\ \text { Dec-00 } & -2.29 & -18.66 & 0.83 & 31.44 \\ \text { Dec-01 } & -2.29 & -18.98 & 0.83 & 29.88 \\ \text { Dec-02 } & -2.21 & -20.91 & 0.83 & 32.38 \\ \text { Dec-03 } & -2.20 & -20.53 & 0.82 & 30.25 \\ \text { Dec-04 } & -2.22 & -18.62 & 0.83 & 28.81 \\ \text { Dec-05 } & -2.22 & -20.10 & 0.83 & 34.99 \\ \text { Dec-06 } & -2.19 & -21.99 & 0.83 & 38.44 \\ \text { Dec-07 } & -2.21 & -20.83 & 0.83 & 34.53 \\ \text { Dec-08 } & -2.24 & -19.08 & 0.82 & 28.04 \\ \text { Dec-09 } & -2.20 & -16.59 & 0.79 & 21.48\end{array}$

Table 9: Estimated states and t-statistics for the France 1978-2009 